\title{
Biodiversity and host-parasite cophylogeny of Sphaerospora (sensu stricto) (Cnidaria: Myxozoa)
}

Sneha Patra ${ }^{1,2}$, Pavla Bartošová-Sojková ${ }^{1}$, Hana Pecková ${ }^{1}$ Ivan Fiala ${ }^{1,2}$, Edit Eszterbauer ${ }^{3}$ and Astrid S. Holzer ${ }^{1,2^{*}}$

\begin{abstract}
Background: Myxozoa are extremely diverse microscopic parasites belonging to the Cnidaria. Their life-cycles alternate between vertebrate and invertebrate hosts, predominantly in aquatic habitats. Members of the phylogenetically well-defined Sphaerospora (sensu stricto) clade predominantly infect the urinary system of marine and freshwater fishes and amphibians. Sphaerosporids are extraordinary due to their extremely long and unique insertions in the variable regions of their 185 and 285 rDNA genes and due to the formation of motile proliferative stages in the hosts' blood. To date, DNA sequences of only 19 species have been obtained and information on the patterns responsible for their phylogenetic clustering is limited.

Methods: We screened 549 fish kidney samples from fish of various geographical locations, mainly in central Europe, to investigate sphaerosporid biodiversity microscopically and by 185 rDNA sequences. We performed multiple phylogenetic analyses to explore phylogenetic relationships and evolutionary trends within the Sphaerospora (s.s.) clade, by matching host and habitat features to the resultant $18 \mathrm{~S}$ rDNA trees. The apparent co-clustering of species from related fish hosts inspired us to further investigate host-parasite co-diversification, using tree-based (CoRE-PA) and distance-based (ParaFit) methods.
\end{abstract}

Results: Our study considerably increased the number of 185 rDNA sequence data for Sphaerospora (s.s.) by sequencing 17 new taxa. Eight new species are described and one species (Sphaerospora diminuta Li \& Desser, 1985) is redescribed, accompanied by sufficient morphological data. Phylogenetic analyses showed that sphaerosporids cluster according to their vertebrate host order and habitat, but not according to geography. Cophylogenetic analyses revealed a significant congruence between the phylogenetic trees of sphaerosporids and of their vertebrate hosts and identified Cypriniformes as a host group of multiple parasite lineages and with high parasite diversity.

Conclusions: This study significantly contributed to our knowledge of the biodiversity and evolutionary history of the members of the Sphaerospora (s.s.) clade. The presence of two separate phylogenetic lineages likely indicates independent historical host entries, and the remarkable overlap of the larger clade with vertebrate phylogeny suggests important coevolutionary adaptations. Hyperdiversification of sphaerosporids in cypriniform hosts, which have undergone considerable radiations themselves, points to host-driven diversification.

Keywords: Myxozoa, Sphaerospora sensu stricto, Taxonomy, Phylogeny, Teleost, Host-parasite codiversification

\footnotetext{
* Correspondence: astrid.holzer@paru.cas.cz

'Institute of Parasitology, Biology Centre, Czech Academy of Sciences, 37005

České Budějovice, Czech Republic

${ }^{2}$ Faculty of Science, University of South Bohemia, 37005 České Budějovice,

Czech Republic

Full list of author information is available at the end of the article
}

(c) The Author(s). 2018 Open Access This article is distributed under the terms of the Creative Commons Attribution 4.0 International License (http://creativecommons.org/licenses/by/4.0/), which permits unrestricted use, distribution, and reproduction in any medium, provided you give appropriate credit to the original author(s) and the source, provide a link to the Creative Commons license, and indicate if changes were made. The Creative Commons Public Domain Dedication waiver (http://creativecommons.org/publicdomain/zero/1.0/) applies to the data made available in this article, unless otherwise stated. 


\section{Background}

The Myxozoa Grassé, 1970 is a diverse group of cnidarian fish parasites, which is composed of over 2400 species [1]. The genus Sphaerospora Thélohan, 1892 consists of 102 described species with $18 S$ rDNA sequences presently available for only 24 taxa (NCBI database, December 2017). Myxospores from vertebrate hosts are spherical to subspherical with two identical valves, a single binucleated or 2-12 uninucleated sporoplasms and two subspherical polar capsules situated perpendicular to the sutural plane [2, 3]. Sphaerospora (sensu stricto) (s.s.) is a phylogenetic clade of myxozoans that hosts the type-species Sphaerospora elegans Thélohan, 1892 and 18 other species considered "true sphaerosporids" [4-7]. Extremely long insertions in the variable regions of $18 S$ and $28 S$ rDNA genes are exclusive features of this unique clade of myxozoans $[4,5,8]$ which define the clade. Sphaerospora molnari Lom, Dyková, Pavlasková \& Grupcheva, 1983 possesses one of the longest eukaryotic $18 S$ rDNA sequences (3.7 kb) [9].

Most of the members of Sphaerospora (s.s.) are coelozoic in the excretory system (predominantly renal tubules), only two histozoic taxa, i.e. Sphaerospora fugu (Tun, Yokoyama, Ogawa \& Wakayabashi, 2000) and $S$. molnari, have been sequenced to date. Members of Sphaerospora (s.s.) are believed to have similar life-cycle strategy like other myxozoans that alternate between vertebrate and invertebrate hosts $[5,10]$. Life-cycles were described for Sphaerospora truttae Fischer-Scherl, El-Matbouli \& Hoffmann, 1986 [11] and Sphaerospora dykovae Gunter \& Adlard, 2010 [12] but that of S. truttae was later shown to be incorrect as the alternate spore stages from the two hosts did not have identical $18 S$ rDNA sequences [13], while the invertebrate lifecycle stage of $S$. dykovae still requires molecular confirmation [14]. Vertebrate hosts for sphaerosporids are marine and freshwater teleost fishes as well as amphibians $[4,5,15]$.

The evolution of parasites and their hosts is shaped by their reciprocal influence and it was recently demonstrated that myxozoans and their invertebrate hosts show a high degree of phylogenetic congruence, likely because the latter represent the host group that was first acquired by myxozoans [16]. Cophylogenetic signal between myxozoans and their vertebrate hosts is more obscured as the coevolutionary history of reciprocal adaptation of myxozoans and their intermediate vertebrate hosts is much shorter and is received as a "mixed signal" of invertebrate and vertebrate cophylogeny [16]. Myxozoans are potentially the fastest evolving metazoans on the planet [16-20], with the most radical nucleotide variability found in true sphaerosporids. This group has also a wide range of vertebrate hosts, making them an especially interesting case for cophylogenetic studies. Lack of data for sphaerosporids in a recent study evaluating reciprocal dependencies of the phylogenies of myxozoans and their vertebrate hosts led to inconsistent results in this clade [16].

In the present study, we screened fish kidneys specifically for sphaerosporids, provide descriptions of a wide spectrum of Sphaerospora spp. accompanied by data on host specificity and $18 S$ rDNA sequences that significantly enrich the dataset for phylogenetic and cophylogenetic analyses. We reinvestigated host-parasite codivergence using an extended sphaerosporid dataset, allowing for a detailed analysis of interdependent phylogenies and recreation of the evolutionary history of this special group of myxozoan parasites.

\section{Methods}

Sample collection and parasite morphology

In total, 549 fishes belong to 28 species (542 from freshwater and 7 from marine habitats) were collected from various localities, mostly in the Czech Republic (Additional file 1: Table S1), between 2012 and 2017. The highest number of fishes belongs to the order Cypriniformes (424 fish, 16 species) and Perciformes (82 fish, 3 species). All captured fish were euthanized by an overdose of clove oil followed by neural pithing. Kidney samples from all fishes were collected using sterile scissors and scalpel blades. Kidney samples were freshly squashed on grease-free glass slides and checked under an Olympus BX51 microscope, followed by digital documentation of kidneys containing presporogonic stages and Sphaerospora spores, using an Olympus DP70 camera. Preliminary species identification was performed referring to published guidelines [3, 21, 22]. Spores were measured on digital images using ImageJ 1.48q (Wayne Rasband, http://imagej.nih.gov/ij, Java 1.7.0_45; 64 bit) in reference to graticule measurements. Spore measurements (in $\mu \mathrm{m}$ ) include spore length (L) and thickness $(\mathrm{T})$, polar capsule length (PL) and width (PW), as well as plasmodium length and width given as the range followed by the mean in parentheses. The ratio of spore length to thickness $(\mathrm{L} / \mathrm{T})$ was also calculated to better describe spore shape.

\section{$18 S$ rDNA amplification}

For DNA analyses, all kidneys (including those considered uninfected by microscopical examination) were fixed in $400 \mu \mathrm{l}$ TNES urea buffer [23]. Standard phenolchloroform DNA extraction was performed after proteinase- $\mathrm{K}$ digestion and the obtained DNA was eluted in 50-100 $\mu \mathrm{l}$ DNase/RNase-free PCR grade water. We screened all kidney samples for myxozoan infection by general myxozoan primer combination sets for $18 \mathrm{~S}$ rDNA (primer combination of Erib1 + Erib10 followed by second round PCR with MyxGP2F + Act1R; [14, 24]; 
details in Additional file 2: Table S2, Additional file 3: Table S3, Additional file 4: Table S4). Sphaerospora $18 S$ rDNA sequences were obtained by various combinations of general myxozoan, sphaerosporid and species-specific primer sets with specific amplification conditions (Additional file 2: Table S2 and Additional file 4: Table S4). Taq-Purple DNA polymerase (Top-Bio, Prague, Czech Republic) or the more sensitive TITANIUM Taq DNA polymerase (Takara Bio Europe/Clontech, Saint Germain en Laye, France) was used for PCR amplification (Additional file 2: Table S2). PCR products were extracted with the Gel/PCR DNA Fragments Extraction Kit (Geneaid Biotech Ltd., New Taipei City, Taiwan) and sequenced commercially (www.SEQme.eu). All obtained sequences were checked thoroughly for clear chromatograms. In case of mixed sphaerosporid infection, amplicons were cloned into the pDrive vector using the PCR Cloning Kit (Qiagen, Hilden, Germany), and transformed into TOP10 chemically competent Escherichia coli cells (Life Technologies, Prague, Czech Republic). Plasmid DNA was isolated by a High Pure Plasmid Isolation Kit (Roche Applied Science, Mannheim, Germany) and three colonies from each PCR product were sequenced commercially. Newly generated sequences were submitted to BLAST (NCBI) for their preliminary identification. Partial sequences were assembled in SeqMan II, DNAStar package v5.05 (DNASTAR Inc., Madison, Wisconsin, USA).

\section{$18 S$ rDNA sequence alignment and analyses}

Thirty-eight sphaerosporid $18 S$ rDNA sequences were aligned in MAFFT v7.017 [25] implemented in Geneious v8.0.5 [26] by L-INS-i algorithm, scoring matrix 200PAM/k=2 with gap opening penalty of 1.0 and offset value of 0.1 . Due to large insertions in $18 \mathrm{~S} \mathrm{rDNA}$ variable regions, the alignment was edited manually in Geneious v8.0.5. The complete alignment including extensive species-specific insertions was 4813 bp long (Additional file 5). GC-content was calculated for all newly obtained $18 S$ rDNA sequences using EditSeq, DNAStar package v5.05 (DNASTAR Inc., Madison, Wisconsin, USA) (Additional file 6: Table S5). Subsequently, nucleotides from extensive long insertions were deleted based on comparison with secondary structure-based alignments [8], resulting in a dataset of 3579 bp which was used for phylogenetic analyses. The distance matrix was produced in Geneious v8.0.5 from the same alignment file after excluding very short partial $18 S$ rDNA sequences obtained from Sphaerospora sp. ex Gobio gobio (L.), Sphaerospora sp. ex Rutilus rutilus (L.), Sphaerospora elopi n. sp. and Sphaerospora hankai (Additional file 7: Table S6). A more restricted dataset consisting only of Sphaerospora spp. obtained from cypriniform hosts (15 taxa, $3768 \mathrm{bp}$ ) was produced as it allowed the inclusion of additional informative positions was aligned as described above. Two independent $18 S$ rDNA datasets were produced to calculate (i) the intraspecific divergence of Sphaerospora diversa n. sp. (3 sequences; 3112 bp; Additional file 8: Table S7); and (ii) the interspecific divergence of sphaerosporids obtained from $R$. rutilus (2 sequences; 917 bp; not shown).

\section{Phylogenetic analyses}

Maximum likelihood analysis (ML) was performed using RAxML v7.2.8 [27] implemented in Geneious v8.0.5 with the GTR $+\Gamma$ model of evolution and 500 bootstrap replicates. jModelTest [28] was used to select the bestfitting model of sequence evolution using corrected Akaike information criterion. Maximum parsimony analysis (MP) was performed in PAUP* v4.b10 [29], using a heuristic search with random taxa addition, the ACCTRAN option and TBR swapping algorithm with bootstrapping analysis for 1000 replicates, gaps were treated as missing data and all characters treated as unordered. Bayesian inference analysis (BI) was performed in MrBayes v3.2.6 [30] implemented in Geneious v8.0.5, using the GTR $+\Gamma$ model. Posterior probabilities were estimated from 1,000,000 generations by two independent runs of simultaneous Markov Chain Monte Carlo chains with every 100th tree saved. 'Burn-in' period was set to $10 \%$; Tracer v1.6 [31] was used to set the length of 'burn-in' period.

\section{Cophylogenetic analyses}

Unavailability of mitochondrial data for certain hosts of the 38 sphaerosporids led to replacement of mitogenome sequences with those of closely related species (5 host taxa), while 3 sphaerosporid taxa were withdrawn from the analysis due to unavailability of closely related/congeneric host mitogenome sequences. In addition, 4 partial sphaerosporid $18 S$ rDNA sequences were excluded due to their short length (details in Additional file 9: Table S8). Hence, for host-parasite cophylogenetic analyses, an alignment of $3118 S$ rDNA Sphaerospora (s.s.) sequences (3579 bp) was analysed in combination with an alignment of 24 complete host mitogenomes (15 591 bp) available on GenBank (NCBI) (November 2017). Parasite and host ML trees were produced using RAxML v7.2.8 as previously mentioned. Host-parasite cophylogeny was evaluated using an event-based tree topology method, CoRe-PA v0.5.1 [32] without a priori cost assignment, checking $10^{4}$ cost sets using the simplex method on the quality function. Statistical significance was tested by randomizing host and parasite topologies (10,000 random trees used) under the proportion-todistinguishable model. As a second method, we determined Global fit based on patristic distances (Geneious v8.0.5, above-mentioned dataset) and independent from 
tree topologies, in ParaFit [33], implemented in the APE package v3.4 [34] in R v3.2.4 (R Core Team 2013).

\section{Results}

\section{Infection prevalence in fish}

Light microscopic observation determined the presence of early presporogonic stages in the kidney tubules of 101 fish (101/549, 18\%) with mature sphaerosporid spores in 16 fish kidney samples (16/549, 3\%) (Fig. 1, Tables 1 and 2, Additional file 1: Table S1). PCR screening confirmed "true sphaerosporid" identity of all 16 fish kidneys with sporogonic stages. Moreover, 5 fish kidneys with early presporogonic stages and 5 fish kidneys without any visible infection were PCR-positive for Sphaerospora (s.s.). Overall prevalence of sphaerosporid infection was very low $(26 / 549,5 \%)$ (Tables 1 and 2, Additional file 1: Table S1). Abramis brama (L.), Rutilus rutilus, Scardinius erythrophthalmus (L.) and Squalius cephalus (L.) were found to host multiple sphaerosporid infections. Sphaerospora diversa n. sp. was found in three host species from three distinct locations (Table 1). The remaining presporogonic stages $(96 / 549,18 \%)$ belonged to malacosporeans or Hoferellus spp. Spores of nonsphaerosporid myxozoans were found in 108 kidney samples $(108 / 549,20 \%)$.

\section{Sphaerosporid species diversity and descriptions}

Based on strongly divergent sequences in the variable sections of the $18 \mathrm{~S}$ rDNA gene region, 17 new $18 \mathrm{~S}$ rDNA sequences of were obtained from the fish examined in the present study. Based on morphology, Sphaerospora diminuta Li \& Desser, 1985 was identified and redescribed from Lepomis gibbosus (L.) caught in the Czech Republic (Fig. 1a and b, Table 2). Eight taxa are new species for which we provide morphological and molecular data. The lack of microscopically detectable mature and immature spores or the presence of mixed sphaerosporid infections prevent us from identifying the other eight sphaerosporids detected by 18S rDNA sequencing (Tables 1 and 2, Additional file 1: Table S1) from A. brama, Ctenopharyngodon idella (Valenciennes), Gobio gobio, Lota lota (L.), Sander lucioperca (L.), S. erythrophthalmus, Silurus glanis L. and $R$. rutilus. These may represent new species or
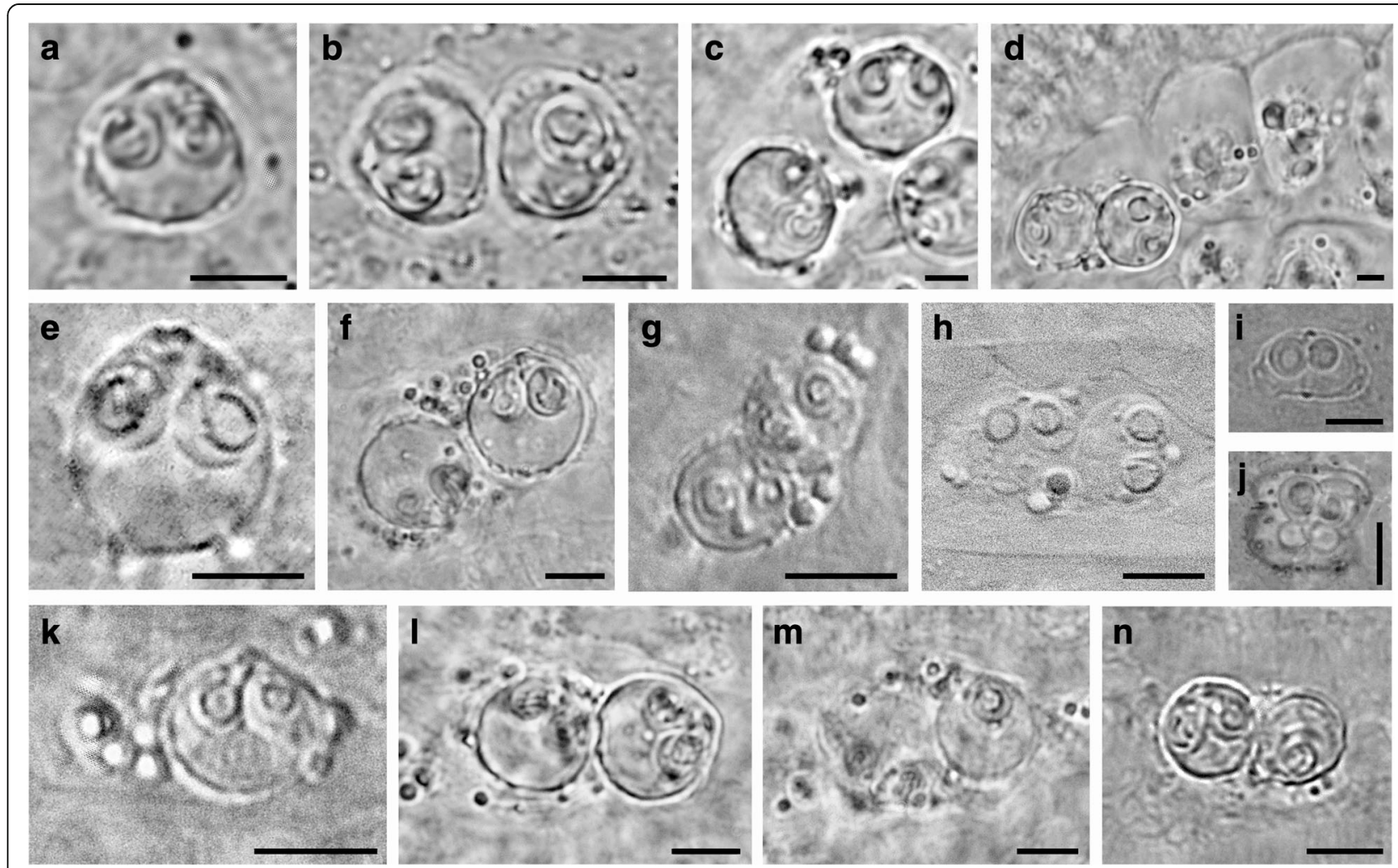

Fig. 1 Sphaerosporid pseudoplasmodia and spores within the renal tubules of different fish hosts. a Mature spore of Sphaerospora diminuta. $\mathbf{b}$ Disporic pseudoplasmodium of S. diminuta. c Mature spores of Sphaerospora abrami n. sp. d Disporic pseudoplasmodium of S. abrami n. sp. e Mature spore of Sphaerospora bliccae n. sp. $\mathbf{f}$ mature spores of Sphaerospora dentata n. sp. $\mathbf{g}$ Disporic pseudoplasmodium of Sphaerospora diversa n. sp. ex Leuciscus leuciscus. $\mathbf{h}$ Disporic pseudoplasmodium of S. diversa n. sp. ex Squalius cephalus. i Mature spore of Sphaerospora elopi n. sp. j Disporic pseudoplasmodium of S. elopi n. sp. k Mature spore of Sphaerospora gutta n. sp. I Disporic pseudoplasmodium of S. rutili n. sp. $\mathbf{m}$ Monosporic pseudoplasmodium of Sphaerospora rutili $\mathrm{n}$. sp. $\mathbf{n}$ Disporic pseudoplasmodium of Sphaerospora squalii n. sp. Scale-bars: $5 \mu \mathrm{m}$ 


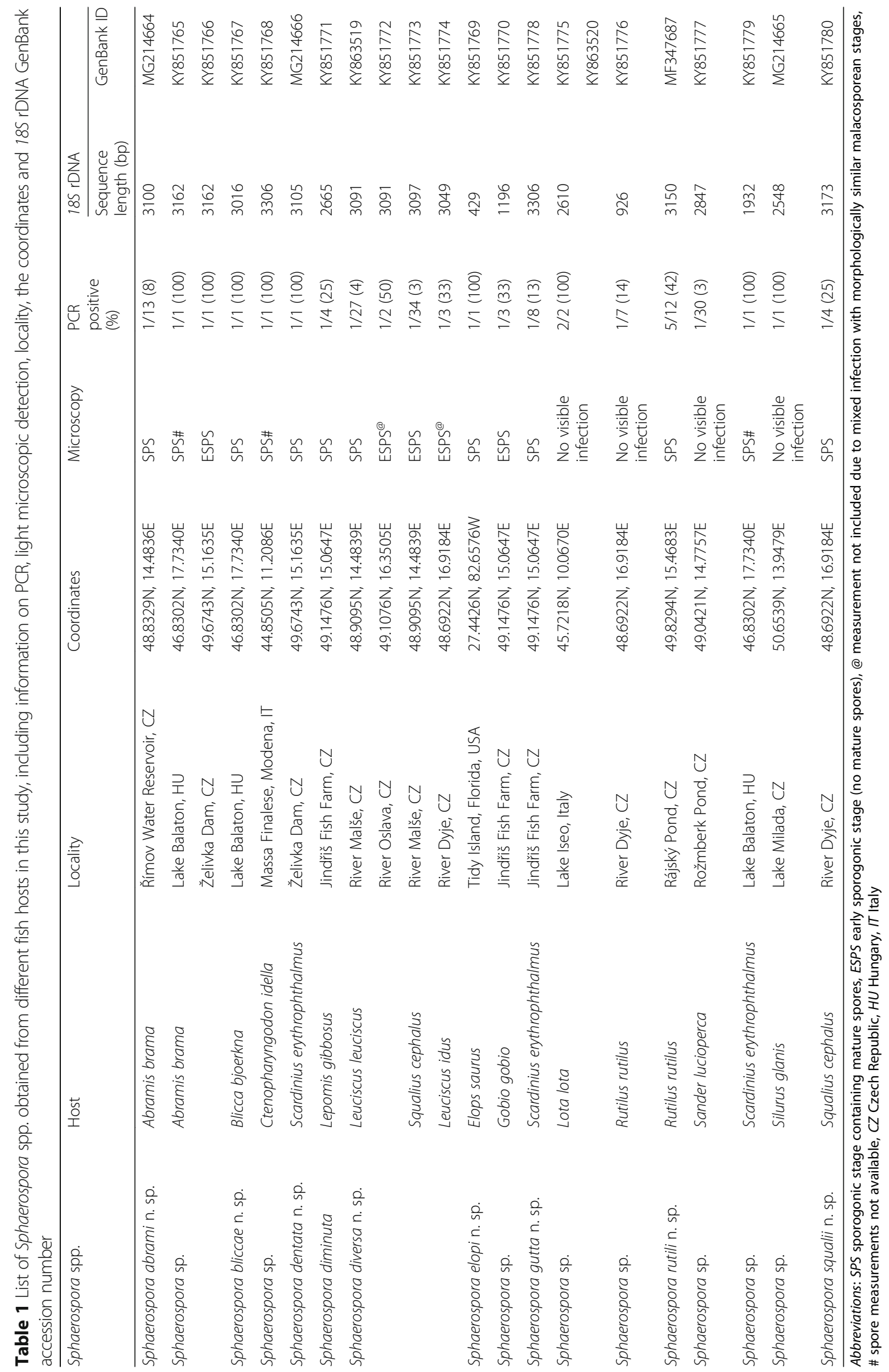




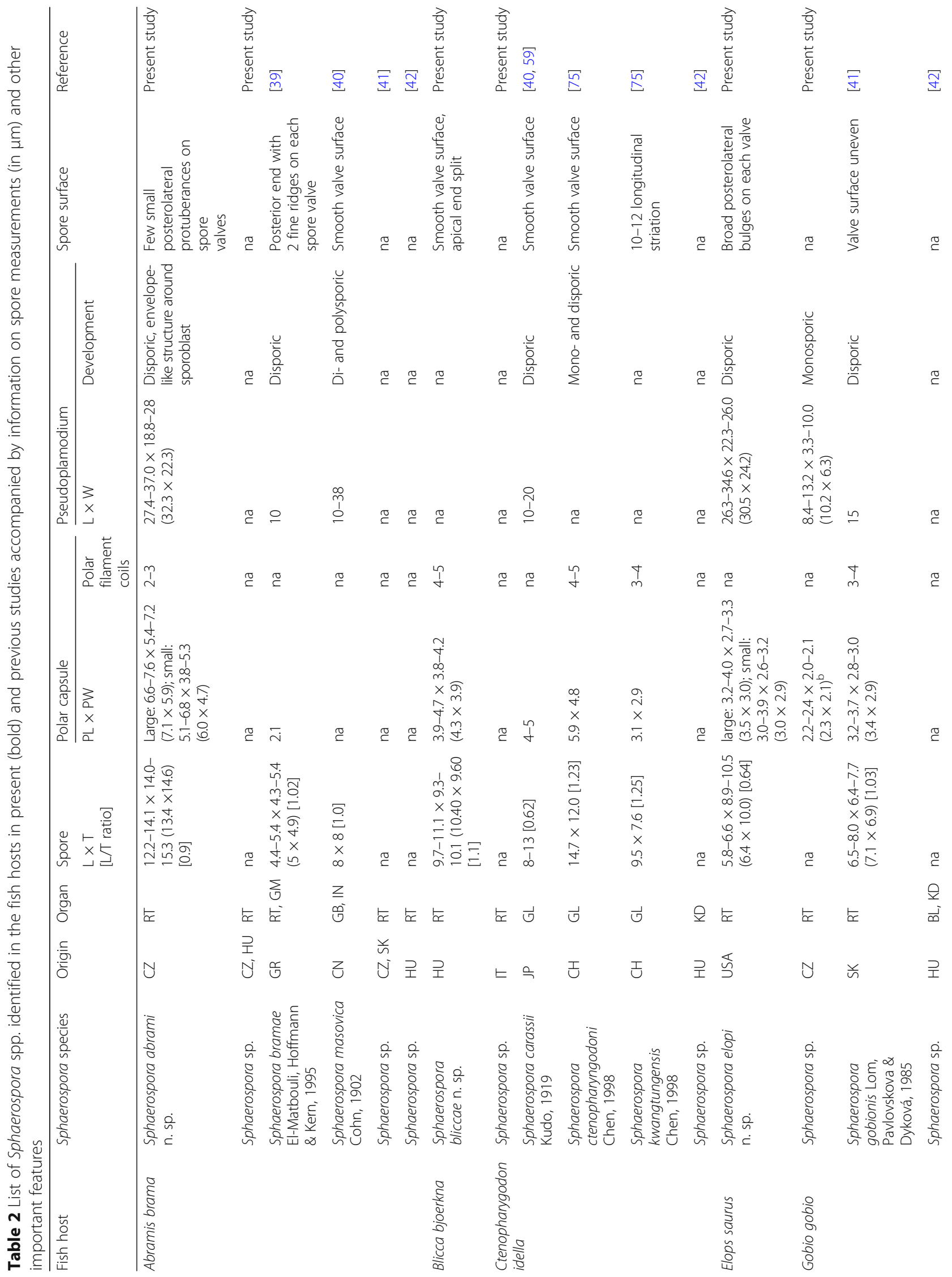




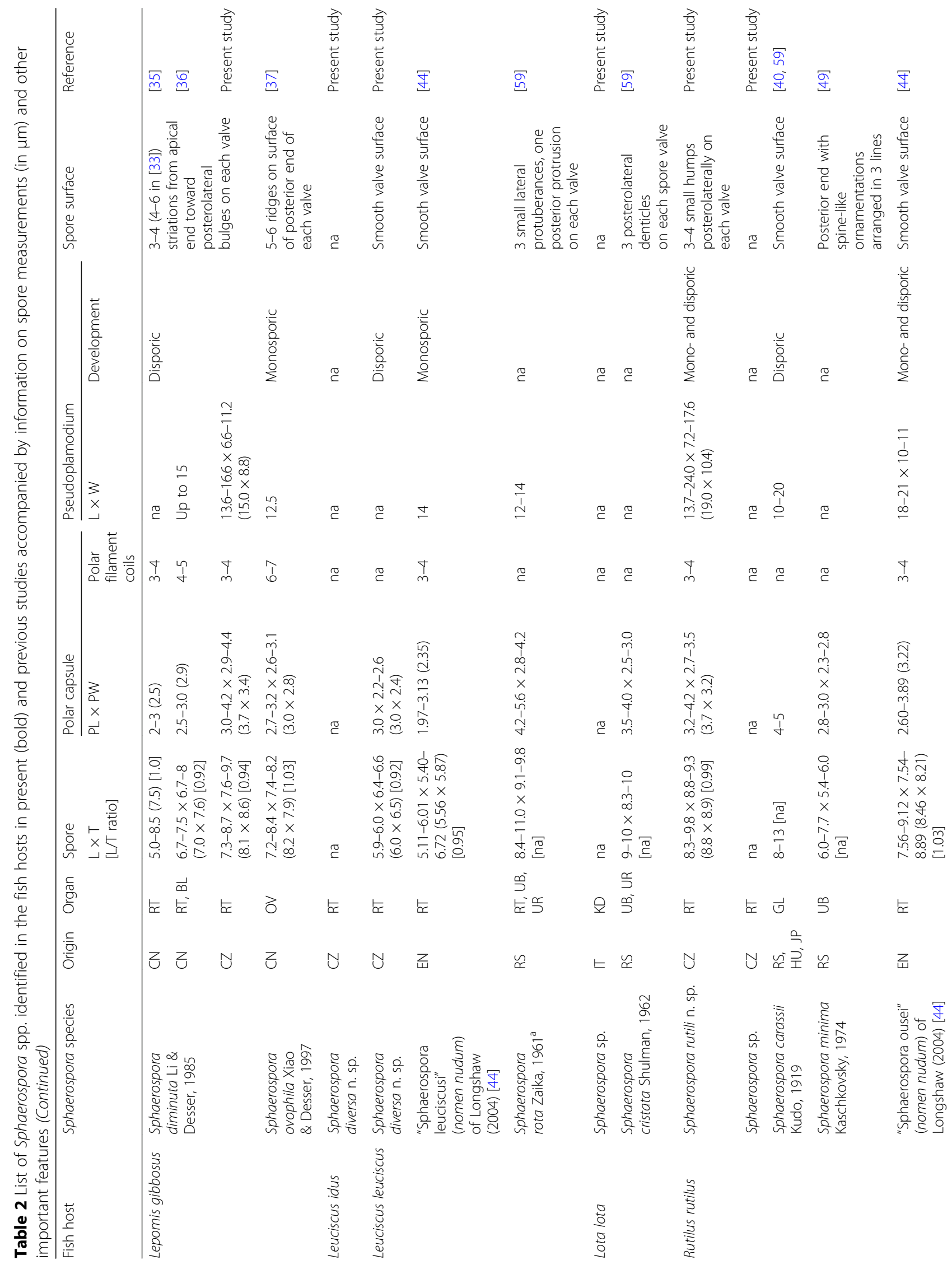




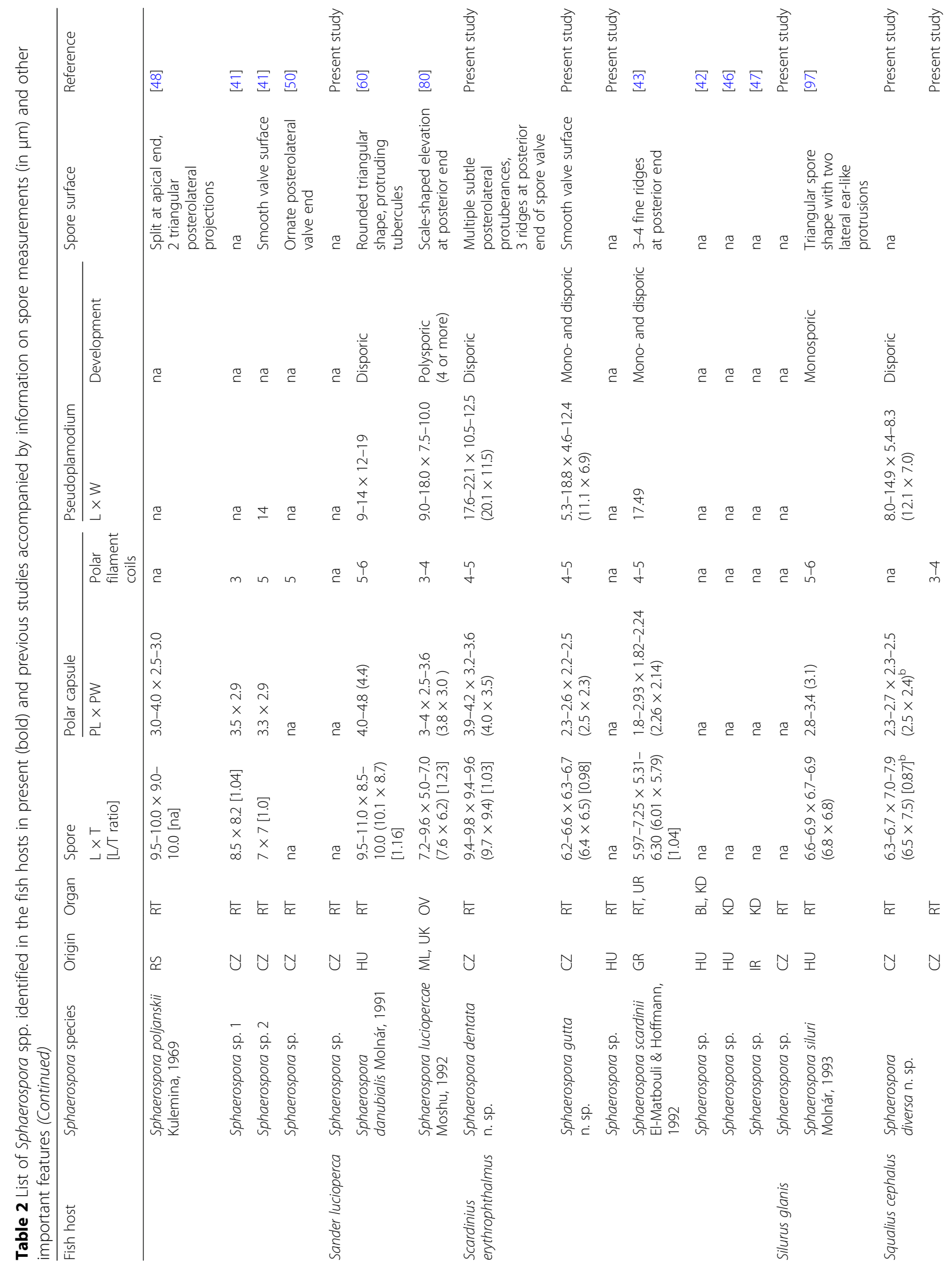




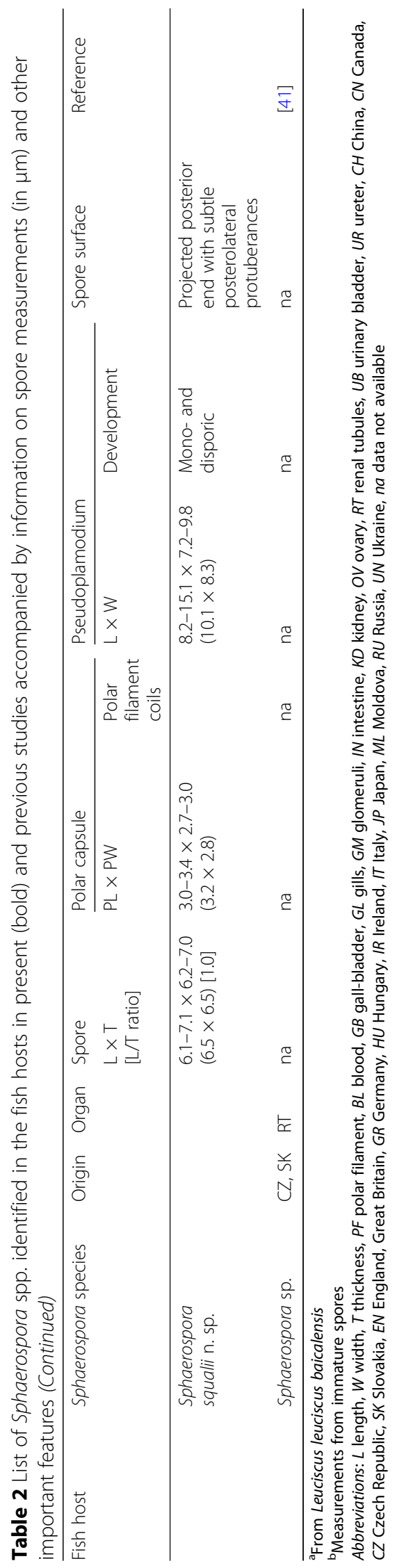


species that have been previously described or recorded in these hosts (Table 2).

\section{Descriptions of species of Sphaerospora}

Phylum Cnidaria Hatschek, 1888

Unranked subphylum Myxozoa Grassé, 1970

Class Myxosporea Bütschli, 1881

Order Bivalvulida Schulman, 1959

Suborder Variisporina Lom \& Noble, 1984

Family Sphaerosporidae Davis, 1917

Genus Sphaerospora Thélohan, 1892

\section{Sphaerospora diminuta Li \& Desser 1985}

Type-host: Lepomis gibbosus (L.) (Centrarchiformes: Centrarchidae), pumpkinseed.

Type-locality: Lake Sasajewun, Ontario [35, 36].

Other locality: Jindřiš fish farm (49.1476N, 15.0647E),

Czech Republic (present study).
Voucher material: Series of photomicrographs, and a representative DNA sample was deposited at the Protistological Collection of the Institute of Parasitology, Biology Centre, Czech Academy of Sciences, České Budějovice (accession number IPCAS Prot 47).

Site in host: Lumen of renal tubules and ureters.

Prevalence: 20\% (2/10) [35], 18\% (7/40) [36] and 25\% (1/ 4) (present study).

Representative DNA sequence: A partial $18 S$ rDNA sequence of 2665 bp was deposited in the GenBank database under the accession number KY851771.

\section{Redescription}

Spore. Mature spores subspherical with pointed apical end, measuring 7.3-8.7 × 7.6-9.7 (8.1 × 8.6) $(\mathrm{L} \times \mathrm{T}, n=$ 6) (Figs. 1a and 2a). Spores with 2 equally-sized subspherical polar capsules, $3.0-4.2 \times 2.9-4.4(3.7 \times 3.4)(\mathrm{PL} \times$ PW, $n=12)$. Polar filaments with $3-4(n=6)$ coils per polar capsule. Spore valves with 3-4 longitudinal striations, with posterolateral bulges on each valve; sutural
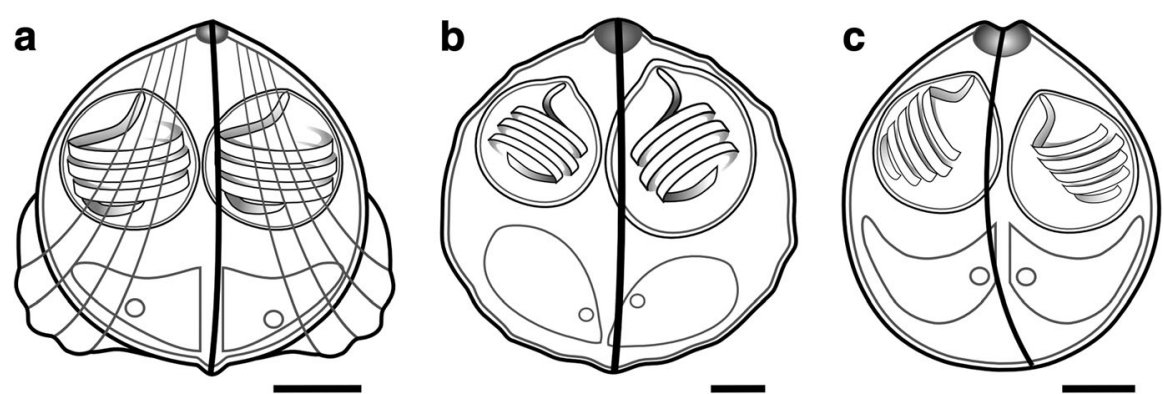

d
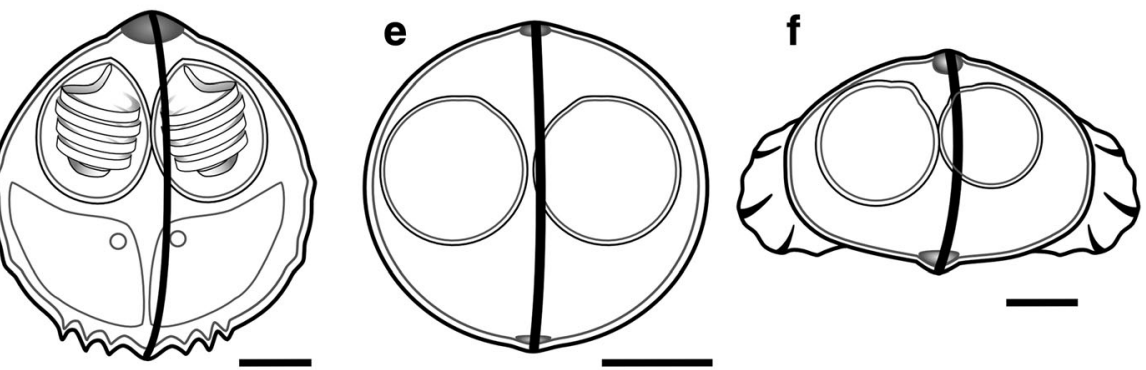

g
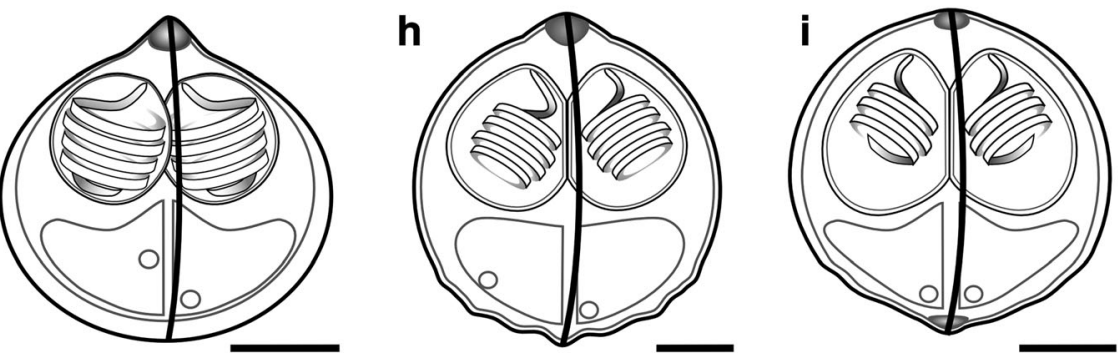

Fig. 2 Line drawings of the Sphaerospora spp. spores obtained from renal tubules of different fish hosts. a Sphaerospora diminuta. b Sphaerospora abrami n. sp. c Sphaerospora bliccae n. sp. d Sphaerospora dentata n. sp. e Sphaerospora diversa n. sp. ex Leuciscus leuciscus. f Sphaerospora elopi n. sp. g Sphaerospora gutta n. sp. h Sphaerospora rutili n. sp. i Sphaerospora squalii n. sp. Scale-bars: $2 \mu \mathrm{m}$ 
line straight, prominent, with sutural ridge protruding slightly at spore apex. Sporoplasms 2, uninucleate.

Pseudoplasmodium. Disporic pseudoplasmodia measuring $13.6-16.6 \times 6.6-11.2(15.0 \times 8.8)(n=9)$, with numerous refractile granules (Fig. 1b).

\section{Remarks}

Spore measurements, spore surface ornamentation, development of disporic pseudoplasmodia, host tissue localization and the number of polar filament coils match the original description of S. diminuta [35] and its later report [36] though motility of the pseudoplasmodia and higher number of spore surface striations (4-6 vs 3-4) reported by Lom et al. [36] were not observed in the present study (Table 2). In addition, extrasporogonic blood stages were observed by Lom et al. [36]. For the first time, we are providing $18 \mathrm{~S}$ rDNA sequence data of this species. Another species, Sphaerospora ovophila Xiao \& Desser, 1997 from the ovary of $L$. gibbosus significantly differs by spore measurements, number of polar filament coils, L/T ratio (Table 2), formation of monosporic pseudoplasmodia and tissue localization. Additionally, ornamental folds (pits) in $S$. ovophila occur only on the posterior end of the spores which contrasts ridges overarching the whole spore and the additional presence of posterolateral bulges in $S$. diminuta (Table 2) [37].

\section{Sphaerospora abrami n. sp.}

Type-host: Abramis brama (L.) (Cypriniformes: Leuciscidae), common bream.

Type-locality: Ř́mov Water Reservoir (48.8329N, 14.4836E), Czech Republic.

Type-material: Hapantotypes: series of phototypes, deposited together with a representative DNA sample in the Protistological Collection of the Institute of Parasitology, Biology Centre, Czech Academy of Sciences, České Budějovice (accession number IPCAS Prot 44).

Site in host: Lumen of renal tubules.

Prevalence: 8\% (1/13).

Representative DNA sequence: A partial $18 S \mathrm{rDNA}$ sequence of 3100 bp was deposited in the GenBank database under the accession number MG214664.

ZooBank registration: To comply with the regulations set out in article 8.5 of the amended 2012 version of the International Code of Zoological Nomenclature (ICZN) [38], details of the new species have been submitted to ZooBank. The Life Science Identifier (LSID) of the article is urn:lsid:zoobank.org:pub:CFA20253-62B5-4BC0-8F302C054C1DB0D9. The LSID for the new name Sphaerospora abrami is
urn:lsid:zoobank.org:act:F2B82DC9-697E-48C5-8E99-

56C8BFA414BB.

Etymology: The species epithet "abrami" is derived from the type-host species name Abramis brama.

\section{Description}

Spore. Mature spores subspherical, with pointed apical end, measuring 12.2-14.1 × 14.0-15.3 $(13.4 \times 14.6)(\mathrm{L} \times$ $\mathrm{T}, n=6$ ) (Figs. 1c and 2b). Spores with 2 unequallysized subspherical polar capsules; larger capsule measuring 6.6-7.6 × 5.4-7.2 (7.1 × 5.9) $(\mathrm{PL} \times \mathrm{PW}, n=6)$; smaller capsule measuring 5.1-6.8 $\times$ 3.8-5.3 $(6.0 \times 4.7)$ $(\mathrm{PL} \times \mathrm{PW}, n=6)$. Polar filaments with $2-3(n=8)$ coils per polar capsule. Spore surface smooth with few small posterolateral protuberances; sutural line straight, prominent, with sutural ridge protruding slightly at anterior end. Sporoplasms 2, uninucleate.

Pseudoplasmodium. Disporic pseudoplasmodia measuring 27.4-37.0 × 18.8-28.0 $(32.3 \times 22.3)(n=11)$, with numerous refractile granules (Fig. 1d).

\section{Remarks}

There are two sphaerosporids described from A. brama, Sphaerospora bramae El-Matbouli, Hoffmann \& Kern, 1995, infecting the renal tubules was described from Germany [39] and Sphaerospora masovica Cohn, 1902, infecting the gall-bladder and intestine from Canada [40]. Both species are much smaller than the present species, nevertheless, posterior ridges are present on both, S. bramae and S. abrami n. sp. (Table 2). Moreover, pseudoplasmodia of two sphaerosporids (without mature spores) were reported from the renal tubules of the same fish host [41, 42]. In the present study, another species, Sphaerospora sp. ex A. brama (without morphological data) differs by over $11 \%$ from the $18 \mathrm{~S}$ rDNA of S. abrami n. sp., which confirms their distinct species status. Unavailability of molecular data from previously reported species impede further comparisons with the new species.

\section{Sphaerospora bliccae n. sp.}

Type-host: Blicca bjoerkna (L.) (Cypriniformes: Leuciscidae), white bream.

Type-locality: Lake Balaton (46.8302N, 17.7340E), Hungary.

Type-material: Hapantotypes: series of phototypes, deposited together with a representative DNA sample in the Protistological Collection of the Institute of Parasitology, Biology Centre, Czech Academy of Sciences, České Budějovice (accession number IPCAS Prot 45).

Site in host: Lumen of renal tubules. 
Prevalence: $100 \%(1 / 1)$.

Representative DNA sequence: A partial 185 rDNA sequence of 3016 bp was deposited in the GenBank database under the accession number KY851767.

ZooBank registration: To comply with the regulations set out in article 8.5 of the amended 2012 version of the International Code of Zoological Nomenclature (ICZN) [38], details of the new species have been submitted to ZooBank. The Life Science Identifier (LSID) of the article is urn:lsid:zoobank.org:pub:CFA20253-62B5-4BC0-8F302C054C1DB0D9. The LSID for the new name Sphaerospora bliccae is urn:lsid:zoobank.org:act:49618F86-3AFA-44EA-9F915EAB76DBE12C.

Etymology: The species epithet "bliccae" is derived from the type-host species name Blicca bjoerkna.

\section{Description}

Spore. Mature spores subspherical, measuring 9.7-11.1 $\times$ 9.3-10.1 (10.4 $\pm 0.4 \times 9.6 \pm 0.2)(\mathrm{L} \times \mathrm{T}, n=25)$ (Figs $1 \mathrm{e}$ and $2 \mathrm{c}$ ). Each spore with 2 equally-sized subspherical polar capsules, measuring 3.9-4.7 × 3.8-4.2 (4.3 $\pm 0.2 \times$ $3.9 \pm 0.2)(\mathrm{PL} \times \mathrm{PW}, n=37)$. Polar filaments with $4-5$ $(n=9)$ coils. Spore valves smooth, with slightly curved, pronounced sutural line, moderate apical protrusion with marked dent, devoid of any other ornamentation. Sporoplasms 2, uninucleate.

\section{Remarks}

Sphaerosporid blood stages and spores were reported from the kidney of B. bjoerkna [42] but lacked morphological or molecular data for comparison.

\section{Sphaerospora dentata n. sp.}

Type-host: Scardinius erythrophthalmus (L.) (Cypriniformes: Leuciscidae), common rudd.

Type-locality: Želivka Dam (49.6743N, 15.1635E), Czech Republic.

Type-material Hapantotypes: series of phototypes, deposited together with a representative DNA sample in the Protistological Collection of the Institute of Parasitology, Biology Centre, Czech Academy of Sciences, České Budějovice (accession number IPCAS Prot 46).

Site in host: Lumen of renal tubules.

Prevalence: $100 \%$ (1/1).

Representative DNA sequence: A partial $185 \mathrm{rDNA}$ sequence of 3105 bp was deposited in the GenBank database under the accession number MG214666.

ZooBank registration: To comply with the regulations set out in article 8.5 of the amended 2012 version of the International Code of Zoological Nomenclature (ICZN) [38], details of the new species have been submitted to
ZooBank. The Life Science Identifier (LSID) of the article is urn:lsid:zoobank.org:pub:CFA20253-62B5-4BC0-8F302C054C1DB0D9. The LSID for the new name Sphaerospora dentata is urn:Isid:zoobank.org:act:319CE294-0575-4915-8B7D95E956C72D44.

Etymology: The species epithet "dentata" is referred to the tooth-like pointed ridges of the posterior spore valve surface.

\section{Description}

Spore. Mature spores subspherical, with pointed apical end, measuring 9.4-9.8 × 9.4-9.6 (9.7 $\pm 0.3 \times 9.4 \pm 0.4)$ $(\mathrm{L} \times \mathrm{T}, n=18)$ (Figs. $1 \mathrm{f}$ and $2 \mathrm{~d}$ ). Spores with 2 equallysized subspherical polar capsules measuring 3.9-4.2 $\times 3$. $2-3.6(4.0 \pm 0.2 \times 3.5 \pm 0.3)(\mathrm{PL} \times \mathrm{PW}, n=36)$. Polar filaments with $4-5(n=20)$ coils per polar capsule. Spore surface with multiple subtle posterolateral protuberances and 3 prominent pointed ridges on posterior end of each spore valve; sutural line straight, prominent, with sutural ridge protruding slightly at anterior pole. Sporoplasms 2, uninucleate.

Pseudoplasmodium. Disporic pseudoplasmodia measuring 17.6-22.1 × 10.5-12.5 $(20.1 \times 11.5)(n=11)$, with numerous refractile granules.

\section{Remarks}

The spore measurements and the development of disporic pseudoplasmodia differentiate $S$. dentata n. sp. from Sphaerospora scardinii El-Matbouli \& Hoffmann, 1992 [43], described from same host. Both species have ridges at the posterior end of the mature spores (Table 2). Further details are provided in Sphaerospora gutta n. sp. Remarks section.

\section{Sphaerospora diversa n. sp.}

Type-host: Leuciscus leuciscus (L.) (Cypriniformes: Leuciscidae), common dace.

Other hosts: Leuciscus idus (L.) (Cypriniformes: Leuciscidae), ide; and Squalius cephalus (Cypriniformes: Leuciscidae), European chub.

Type-locality: River Malše (48.9095N, 14.4839E), Czech Republic.

Other localities: River Oslava (49.1076N, 16.3505E) and River Dyje (48.6922N, 16.9184E), Czech Republic.

Type-material: Hapantotypes: series of phototypes, deposited together with a representative DNA sample in the Protistological Collection of the Institute of Parasitology, Biology Centre, Czech Academy of Sciences, České Budějovice (accession number IPCAS Prot 48).

Site in host: Lumen of renal tubules. 
Prevalence: $3-50 \%$ (details in Table 1).

Representative DNA sequences: Identical partial $18 \mathrm{~S}$ rDNA sequences of 3091 bp obtained from L. leuciscus from two different sites in the Czech Republic were deposited in the GenBank database under accession numbers KY851772 and KY863519. Partial 18S rDNA sequences from L. idus (3049 bp) and S. cephalus (3097 bp) were deposited in the GenBank database under accession numbers KY851774 and KY851773, respectively.

ZooBank registration: To comply with the regulations set out in article 8.5 of the amended 2012 version of the International Code of Zoological Nomenclature (ICZN) [38], details of the new species have been submitted to ZooBank. The Life Science Identifier (LSID) of the article is urn:lsid:zoobank.org:pub:CFA20253-62B5-4BC0-8F302C054C1DB0D9. The LSID for the new name Sphaerospora diversa is urn:Isid:zoobank.org:act:34631CAD-DC47-405C-B3F74D2297A21FE9.

Etymology: The species epithet "diversa" is referred to a widened host specificity (three leuciscinid host species) of the species.

\section{Description}

Spore. Mature spores from Leuciscus leuciscus measuring 5.9-6.0 × 6.4-6.6 $(6.0 \times 6.5)(\mathrm{L} \times \mathrm{T}, n=2)$ with 2 equally-sized subspherical polar capsules measuring 3.0 $\times 2.2-2.6(3.0 \times 2.4)(\mathrm{PL} \times \mathrm{PW}, n=2)($ Figs. $1 \mathrm{~g}$ and $2 \mathrm{e})$. Immature spores from $S$. cephalus measuring 6.3-6.7 $\times$ 7.0-7.9 $(6.5 \times 7.5)(\mathrm{L} \times \mathrm{T}, n=2)$, with 2 equally-sized subspherical polar capsules, measuring 2.3-2.7 × 2.3-2.5 $(2.5 \times 2.4)(\mathrm{PL} \times \mathrm{PW}, n=5)($ Fig. $1 \mathrm{~h})$. Spore surface smooth, without ornamentation; sutural line straight, thick, prominent, slightly protruding at anterior spore end.

Pseudoplasmodium. Disporic pseudoplasmodia from $S$. cephalus measuring 8.0-14.9 × 5.4-8.3 $(12.1 \times 7.0)(n=$ $11)$, with numerous refractile granules.

\section{Remarks}

The low $18 S$ rDNA sequence divergence $(0.29-0.89 \%$ over 3,112 bp; Additional file 8: Table S7) amongst the isolates of $S$. diversa n. sp., similar spore measurements and $\mathrm{L} / \mathrm{T}$ ratios < 1 (Table 2) confirm the conspecificity of these three isolates. So far, only "Sphaerospora leuciscusi" (nomen nudum) of Longshaw (2004) [44] has been described from the kidney of L. leuciscus [44] and Sphaerospora rota Zaika, 1961 has been reported from the kidney of Leuciscus leuciscus baicalensis, a subspecies of dace in Lake Baikal [45]. The present species has similar spore and polar capsule measurements as "S. leuciscusi" although it develops exclusively in monosporic pseudoplasmodia and has different $\mathrm{L} / \mathrm{T}$ ratio (Table 2). Spores of $S$. diversa n. sp. are significantly smaller than those of S. rota (Table 2), which also differs by a strongly protruding sutural edge, three small lateral protuberances and a prominent ridge on the posterior spore pole. Sphaerospora rota may represent a species complex as it was also reported from distantly related cypriniform fish Cobitis taenia L. and salmoniform fish Brachymystax lenok (Pallas) [45]. Molecular data from both S. leuciscusi and $S$. rota are not available for comparison with our reports. No sphaerosporid was previously described from $S$. cephalus and L. idus. Pseudoplasmodia of an undescribed sphaerosporid were reported in the renal tubules of $S$. cephalus [41], without morphological or DNA sequence data for species comparison.

\section{Sphaerospora elopi n. sp.}

Type-host: Elops saurus L. (Elopiformes: Elopidae), ladyfish.

Type-locality: Tidy Island (27.4426N, 82.6576W), Florida, USA.

Type-material: Hapantotypes: series of phototypes, deposited together with a representative DNA sample in the Protistological Collection of the Institute of Parasitology, Biology Centre, Czech Academy of Sciences, České Budějovice (accession number IPCAS Prot 49).

Site in host: Lumen of renal tubules.

Prevalence: $100 \%(1 / 1)$.

Representative DNA sequence: A partial $185 \mathrm{rDNA}$ sequence of 429 bp was deposited in the GenBank database under the accession number KY851769.

ZooBank registration: To comply with the regulations set out in article 8.5 of the amended 2012 version of the International Code of Zoological Nomenclature (ICZN) [38], details of the new species have been submitted to ZooBank. The Life Science Identifier (LSID) of the article is urn:lsid:zoobank.org:pub:CFA20253-62B5-4BC0-8F302C054C1DB0D9. The LSID for the new name Sphaerospora elopi is urn:lsid:zoobank.org:act:D04A20793D73-46C4-87F6-07DA80C174CC.

Etymology: The species epithet "elopi" is derived from the type-host species name Elops saurus.

\section{Description}

Spore. Mature spores thicker than wide,, measuring 5.8$6.6 \times 8.9-10.5(6.4 \times 10.0)(\mathrm{L} \times \mathrm{T}, n=9)$ (Figs. $1 \mathrm{i}$ and 2f). Polar capsules 2 , unequally-sized, subspherical; larger capsule measuring 3.2-4.0 × 2.7-3.3 $(3.5 \times 3.0)(\mathrm{PL}$ $\times \mathrm{PW}, n=9)$; smaller capsule measuring $3.0-3.9 \times 2.6-$ $3.2(3.0 \times 2.9)(\mathrm{PL} \times \mathrm{PW}, n=9)$. Broad posterolateral bulges present on spore valves of mature spores;.sutural 
line straight, thick, prominent, slightly protruding at both anterior and posterior spore end.

Pseudoplasmodium. Pseudoplasmodia diasporic, measuring 26.3-34.6 × 22.3-26.0 $(30.5 \times 24.2)(n=2)($ Fig. 1j).

\section{Remark}

Elops saurus or other elopid fishes were not previously reported to harbour sphaerosporids.

\section{Sphaerospora gutta n. sp.}

Type-host: Scardinius erythrophthalmus (L.) (Cypriniformes: Leuciscidae), common rudd. Type-locality: Jindřiš Fish Farm (49.1476N, 15.0647E), Czech Republic.

Type-material: Hapantotypes: series of phototypes, deposited together with a representative DNA sample in the Protistological Collection of the Institute of Parasitology, Biology Centre, Czech Academy of Sciences, České Budějovice (accession number IPCAS Prot 50).

Site in host: Lumen of renal tubules.

Prevalence: $13 \%(1 / 8)$.

Representative DNA sequence: A partial $18 \mathrm{SDNA}$ sequence of 3306 bp was deposited in the GenBank database under the accession number KY851778.

ZooBank registration: To comply with the regulations set out in article 8.5 of the amended 2012 version of the International Code of Zoological Nomenclature (ICZN) [38], details of the new species have been submitted to ZooBank. The Life Science Identifier (LSID) of the article is urn:lsid:zoobank.org:pub:CFA20253-62B5-4BC0-8F302C054C1DB0D9. The LSID for the new name Sphaerospora gutta is urn:lsid:zoobank.org:act:165124A93CA4-471F-BD02-44D97AE696D8.

Etymology: The species epithet "ghutta" is referred to the drop-like mature spore shape.

\section{Description}

Spore. Spores drop-shaped, subspherical, measuring 6 . $2-6.6 \times 6.3-6.7(6.4 \times 6.5)(\mathrm{L} \times \mathrm{T}, n=2)$ (Figs. $1 \mathrm{k}$ and $2 \mathrm{~g})$. Spores with 2 equally-sized subspherical polar capsules measuring $2.3-2.6 \times 2.2-2.5(2.5 \times 2.3)(\mathrm{PL} \times \mathrm{PW}$, $n=4)$. Polar filaments with $4-5(n=4)$ coils per polar capsule. Spore surface smooth, sutural line straight, with prominent sutural ridge protruding at anterior spore end. Sporoplasms 2, uninucleate.

Pseudoplasmodium. Pseudoplasmodia mostly monosporic and rarely diasporic, measuring 5.3-18.8 $\times$ 4.6$12.4(11.1 \pm 3.7 \times 6.9 \pm 1.6)(n=22)$, with numerous refractile granules.

\section{Remarks}

Sphaerospora. gutta n. sp. is similar to $S$. scardinii described from the same host when comparing spore measurements, development in mono- and disporic pseudoplasmodia, within-host localization and the number of polar filament coils (Table 2) [43]. However, fine ridges found at the posterior end of $S$. scardinii were never observed in our samples. For similar reasons, the present species differs significantly from $S$. dentata n. sp. (Table 2). $18 \mathrm{~S}$ rDNA data confirm the distinct status of these two new species and another species Sphaerospora sp. ex S. erythrophthalmus, which lacks morphological data (see below and Additional file 7: Table S6). Absence of $18 S$ rDNA data from S. scardinii impedes comparison with this species. Undescribed Sphaerospora spp. were reported in the blood and kidney of $S$. erythrophthalmus but the lack of spore details and molecular data impede further comparison $[42,46,47]$.

\section{Sphaerospora rutili n. sp.}

Type-host: Rutilus rutilus (L.) (Cypriniformes: Leuciscidae), common roach.

Type-locality: Rájský Pond (49.8294N, 15.4683E), Czech Republic.

Type-material: Hapantotypes: series of phototypes, deposited together with a representative DNA sample in the Protistological Collection of the Institute of Parasitology, Biology Centre, Czech Academy of Sciences, České Budějovice (accession number IPCAS Prot 51).

Site in host: Lumen of renal tubules.

Prevalence: $42 \%$ (5/12).

Representative DNA sequence: A partial $18 S \mathrm{rDNA}$ sequence of $3150 \mathrm{bp}$ was deposited in the GenBank database under the accession number MF347687.

ZooBank registration: To comply with the regulations set out in article 8.5 of the amended 2012 version of the International Code of Zoological Nomenclature (ICZN) [38], details of the new species have been submitted to ZooBank. The Life Science Identifier (LSID) of the article is urn:lsid:zoobank.org:pub:CFA20253-62B5-4BC0-8F302C054C1DB0D9. The LSID for the new name Sphaerospora rutili is urn:Isid:zoobank.org:act:F0840208BE48-4913-B3AC-74C72BBBD465.

Etymology: The species epithet "rutili" is derived from the type-host species name Rutilus rutilus.

\section{Description}

Spore. Mature spores almost spherical, with pointed apical end, measuring 8.3-9.8 $\times 8.8-9.3(8.8 \times 8.9)(\mathrm{L} \times \mathrm{T}$, $n=7$ ) (Figs. $1 \mathrm{l}$ and 2h). Spores with 2 equally-sized subspherical polar capsules, measuring 3.2-4.2 × 2.7-3.5 (3. $7 \times 3.2)(\mathrm{PL} \times \mathrm{PW}, n=14)$. Polar filaments with $3-4(n$ 
= 9) coils per polar capsule. Spore valves smooth, with 3-4 small humps at posterolateral end; suture line straight, pronounced, sutural ridge slightly protruding to apical spore end. Sporoplasms 2, uninucleate.

Pseudoplasmodium. Mono- (Fig. $1 \mathrm{~m}$ ) and disporic (Fig. 11) pseudoplasmodia measuring 13.7-24.0 $\times$ 7.2-17.6 $(19.0 \pm 2.7 \times 10.4 \pm 2.5)(n=16)$, with numerous refractile granules.

\section{Remarks}

Sphaerospora rutili $\mathrm{n}$. $\mathrm{sp}$. is morphologically similar to "Sphaerospora ousei" (nomen nudum) of Longshaw (2004) [44] which also possesses two uninucleated sporoplams, develops in mono- and disporic pseudoplasmodia within the renal tubules of roach. However, the ornamentation at the posterior spore end of S. rutili n. sp. was never observed in "S. ousei," which has completely smooth shell valves (Table 2) [44]. Moreover, "S. ousei" has slightly elongated spores contrasting the spores of S. rutili n. sp. which are thicker (Table 2). Another morphologically similar species, Sphaerospora poljanskii Kulemina, 1969 described from the same host, differs from the present species by larger spore dimensions, a split at the apical spore end, the shape of polar capsules and by the presence of two triangular posterolateral projections (Table 2) [48]. Another roach parasite, Sphaerospora minima Kaschkovsky, 1974 has smaller spores and polar capsule dimensions and spine-like ornamentation arranged in three lines at the posterior spore end, contrasting S. rutili n. sp. spores (Table 2) [49]. A Sphaerospora sp. with ornamentation at the spore end and with similar spore dimensions (deduced from the figure scale-bar) was reported from the renal tubules of roach in South Bohemia, Czech Republic [50]. This is likely the same species as in present study; however, further details on spore morphology and development are missing for species comparison. Lom et al. [41] reported two undescribed Sphaerospora spp. from $R$. rutilus from localities in the Czech Republic. Sphaerospora sp. 1 has nearly identical spore and polar capsule measurements and number of polar filament coils as S. rutili $\mathrm{n}$. sp. though their $\mathrm{L} / \mathrm{T}$ ratios are distinct (Table 2). Further details about the spore surface and development are missing for species comparison. Sphaerospora sp. 2 is similar to the present species due to smooth spore surface, identical L/T ratio and ornamentation at the posterior end of the spore but differs by smaller spore size and higher number of polar filament coils (Table 2). Another species from roach, Sphaerospora sp. ex R. rutilus (present study) partially sequenced from Czech Republic differs by 3\% (over 917 bp covering V7 and V8 regions) from $18 S$ rDNA sequences of $S$. rutili n. sp. Lack of morphological details impedes species comparison. Several other reports of Sphaerospora spp. from the blood and the kidney of roach exist but without further morphological and molecular data [42, 43, 46]. Sphaerospora carassii Kudo, 1919 has also been described from roach but from different organs (gills, gall-bladder and intestine) and with different spore dimensions (Table 2) [40].

\section{Sphaerospora squalii n. sp.}

Type-host: Squalius cephalus (L.) (Cypriniformes: Leuciscidae), European chub.

Type-locality: River Dyje (48.6922N, 16.9184E), Czech Republic.

Type-material: Hapantotypes: series of phototypes, deposited together with a representative DNA sample in the Protistological Collection of the Institute of Parasitology, Biology Centre, Czech Academy of Sciences, České Budějovice (accession number IPCAS Prot 52).

Site in host: Lumen of renal tubules.

Prevalence: 25\% (1/4).

Representative DNA sequence: A partial $18 \mathrm{SDNA}$ sequence of $3173 \mathrm{bp}$ was deposited in the GenBank database under the accession number KY851780.

ZooBank registration: To comply with the regulations set out in article 8.5 of the amended 2012 version of the International Code of Zoological Nomenclature (ICZN) [38], details of the new species have been submitted to ZooBank. The Life Science Identifier (LSID) of the article is urn:lsid:zoobank.org:pub:CFA20253-62B5-4BC0-8F302C054C1DB0D9. The LSID for the new name Sphaerospora squalii is urn:Isid:zoobank.org:act:6449D81B-1B2E-4B94-9293816FDD818364.

Etymology: The species epithet "squalii" is derived from the type-host species name Squalius cephalus.

\section{Description}

Spore. Spores almost spherical, measuring 6.1-7.1 $\times 6$. $2-7.0(6.5 \times 6.5)(\mathrm{L} \times \mathrm{T}, n=8)$ (Figs. $1 \mathrm{n}$ and 2i). Each spore with 2 equally-sized subspherical polar capsules, measuring 3.0-3.4 × 2.7-3.0 $(3.2 \times 2.8)(\mathrm{PL} \times \mathrm{PW}, n=$ 16). Polar filaments with $3-4$ coils $(n=16)$. Spore surface smooth, posterior end with subtle posterolateral protuberances; sutural line straight, prominent, slightly protruding at posterior end. Sporoplasms 2, uninucleate.

Pseudoplasmodium.Pseudoplasmodia mostly disporic and rarely monosporic, elongated, measuring 8.2-15.1 $\times 7.2-9.8)(10.1 \times 8.3)(n=13)$, with numerous refractile granules.

\section{Remarks}

This is the first record of sphaerosporid spores described from S. cephalus. Only pseudoplasmodia were reported 
but further details on spore morphology and molecular data are unavailable for comparison [41]. In the present study, we found a morphologically and morphometrically similar Sphaerospora sp. in true minnows (Leuciscinae), i. e. S. diversa n. sp. (Table 2); however the $18 S$ rDNA sequences differ by $15 \%$ (see below and Additional file 7: Table S6), revealing them as two distinct species.

\section{Pathology}

None of the screened fish showed macroscopic or microscopic pathological changes in fresh smears. Infection levels with spore-forming stages were mild and only a limited number of parasites were visible in the tubular lumen.

\section{5 rDNA sequence data}

In total, 17 new $18 S$ rDNA sequences from 26 Sphaerospora (s.s.)-positive fish kidneys were obtained in present study (Table 1; Additional file 1: Table S1 and Additional file 6: Table S5). 18S rDNA sequences obtained for $S$. diversa n. sp. (3 sequences from 3 host species) were complete and nine sequences were almost complete (including regions V1-V8), while another seven represent partial $18 S$ rDNA sequences (details in Additional file 6: Table S5). The comparison of almost complete $18 \mathrm{~S}$ rDNA sequences revealed that nine sphaerosporid species sampled from cypriniform hosts exceed $>3000$ bp in their length while those of non-cypriniform hosts were $<3000 \mathrm{bp}$. The longest $18 \mathrm{~S}$ rDNA sequences were obtained for S. gutta n. sp. (3306 bp) and Sphaerospora sp. ex C. idella (3306 bp) (Table 1, Additional file 6: Table S5). Interspecific sequence divergence based on a trimmed alignment dataset (Additional file 7: Table S6) was overall varying to a great extent ranging from $1.87 \%$ (between S. rutili n. sp. and S. dentata n. sp.) to 59\% (between S. fugu and $S$. abrami n. sp.), intraspecific divergence for $S$. diversa $\mathrm{n}$. sp. was $0.29-0.89 \%$ (Additional file 8: Table S7). Interestingly, the interspecific divergence of sphaerosporids obtained from the same fish host was $11 \%$ (A. brama, covering V3-V8), 3\% (R. rutilus, covering V7-V8; data not shown) and 15\% (S. cephalus, covering V1-V8), respectively. S. dentata n. sp. and S. gutta n. sp. have 7\% (S. erythrophthalmus, covering V1-V8) sequence divergence, whereas both differ $36-37 \%$ from Sphaerospora sp. ex S. erythrophthalmus (covering V5-V8) (Additional file 7: Table S6). The GC-content of the new sphaerosporid $18 S$ rDNA sequences varied between $48-60 \%$ over the whole $18 S$ rDNA and $39-73 \%$ in the variable regions (Additional file 6: Table S5). Sphaerospora diminuta reached the highest overall GC content (60\%). Sphaerospora elopi n. sp. as the only new member of the "primary marine" sphaerosporid clade had a $51 \%$ overall and $49 \%$ variable region (V8) GC content. All new sphaerosporid sequences possess long insertions in the variable regions, especially in $\mathrm{V} 2$, V4 and V7, a characteristic feature of true sphaerosporids (Additional file 6: Table S5).

Having attempted various primer combinations, we found that the following sets most successfully amplified sphaerosporid $18 \mathrm{~S}$ rDNA sequences: (i) general $18 \mathrm{~S}$ rDNA primer combination of Erib1 + Erib10 followed by a second round PCR with a new primer combination for freshwater Sphaerospora spp. SphFWSSU1243F + SphFWSSU3418R (present study); (ii) a Sphaerosporaspecific general primer combination of PsSSU1850F + Erib10 followed by a second round PCR with PsSSU2110F + Erib10 [5]; and (iii) general $18 S$ rDNA primer combination of Erib1 + Erib10 followed by second round PCR with MyxGP2F + Act1R [14, 24] (details in Additional file 2: Table S2). A combination of expanded primer extension time and highly efficient TITANIUM Taq polymerase considerably improved the outcome of PCRs.

\section{Phylogenetic relationships within the Sphaerospora (s.s.) clade}

The phylogenetic tree of $18 \mathrm{~S}$ rDNA sequences including all newly sequenced taxa (Fig. 3) shows that all new sequences cluster within the Sphaerospora (s.s.) clade, allowing us to consider them "true sphaerosporids". The new sequences cluster into two distinct clades: (i) a basal "primary marine" clade of sphaerosporids from marine teleosts (i.e. Lineage $\mathrm{A}$ in [5]); and (ii) all other sphaerosporids (i.e. Lineage $B$ in [5]). The latter, larger clade is subdivided into 3 distinct subclades (Fig. 3): (i) a clade of sphaerosporids from amphibians; (ii) the "secondary marine" clade of sphaerosporids with spores containing 4-12 sporoplasms ( $v s$ otherwise commonly 2) from marine habitats; and (iii) a "freshwater clade" of sphaerosporids from freshwater fishes, which includes the typespecies S. elegans. The freshwater clade is further divided into three subclades including: (i) sphaerosporids from cypriniform hosts; (ii) species from siluriform hosts; and (iii) a subclade of species from mixed fish host families. Sphaerospora molnari, the only histozoic parasite of the freshwater clade for which $18 S$ rDNA sequences are available, creates a distinct sublineage. Sphaerospora diminuta produces a long branch within the mixed host freshwater subclade. Geography did not reflect phylogenetic clustering of sphaerosporids; however, host habitat (freshwater vs marine) and host group (at the ordinal level) showed a clear pattern in certain clades. Sphaerosporids from the same host order clustered 


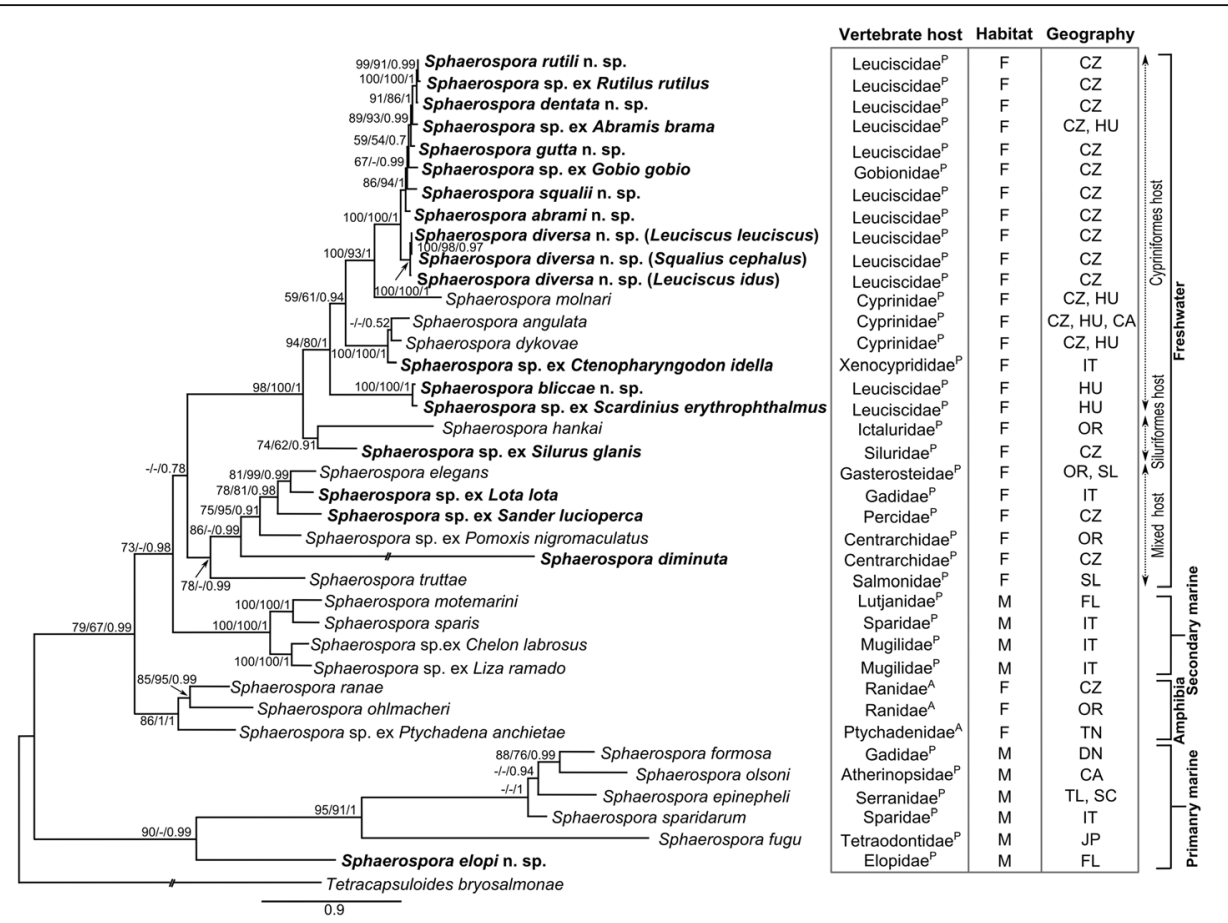

Fig. 3185 rDNA-based maximum likelihood (GTR $+\Gamma$ model) tree of the Sphaerospora (sensu stricto) clade. Tetracapsuloides bryosalmonae was used as the outgroup. Newly sequenced taxa are in bold. Maximum likelihood/maximum parsimony/Bayesian inference nodal supports are shown at every node. Dashes indicate $<50$ nodal support values or a node missing in the maximum parsimony and Bayesian inference analyses. The original length of long branches was shortened to $50 \%$ of their original length (indicated as $-/ /-$-). Superscript letters at the end of the vertebrate host families indicate the host types (P, piscine; and A, amphibian). Abbreviations: F, freshwater; M, marine; CA, California, USA; CZ, Czech Republic; DN, Denmark; FL, Florida, USA; HU, Hungary; IT, Italy; JP, Japan; OR, Oregon, USA; SC, South China Sea; SL, Scotland; TL, Thailand; TN, Tanzania

together in the same clade or in sister clades (e.g. Cypriniformes, Centrarchiformes, Mugiliformes, Siluriformes and Anura) (Fig. 3). However, this trend was not observed at host family level as, for example, sphaerosporids from Gobionidae and Xenocyprididae grouped inside species of Leuciscidae and Cyprinidae, respectively (Fig. 4). Moreover, sphaerosporids from Leuciscidae and Cyprinidae clustered in more than one clade within the phylogenetic tree.

\section{Cophylogeny analyses}

The phylogenetic analysis of vertebrate mitochondrial sequence data revealed a tree topology that is in accordance with recent phylogenomic studies [51, 52], apart from the position of Takifugu rubripes (Eupercaria: Tetraodontiformes: Tetraodontidae) which clustered outside Eupercaria and basal of Percomorphaceae. However, we did not exclude this species from tree reconciliation analysis. In the sphaerosporid phylogenetic tree used for cophylogeny, species clustering was unaltered after excluding six species (see "Cophylogenetic analyses" in Methods section; Additional file 9: Table S8).

The tree topology-based analysis performed in CoRePA detected significant congruence between the phylogenetic trees of sphaerosporids and their vertebrate hosts (Fig. 5), with 18 cospeciation events (estimated cost for cospeciation $=0.105$ ) calculated from a dataset of 24 hosts and 31 parasites. Quality of the reconstruction was $1.8830165 \times 10^{-11}$ with a total cost of 7.578. CoRe-PA estimated 35 sorting (cost 0.054) and three host switching (cost 0.631) events: (i) from $S$. erythrophthalmus to A. brama; (ii) from Gasterosteus aculeatus L. to L. lota; and (iii) from a common perciform ancestor to Merlangius merlangus (L.), where all parasites established and diversified successfully. In cypriniforms, sphaerosporid diversity is presently the highest, based on the sampling performed in this study. In half of investigated cypriniform hosts, two independent sphaerosporid lineages are present. Furthermore, the analysis showed that the oldest cypriniforms already had three independent parasite lineages, indicating an extremely successful radiation of sphaerosporids in this host group. Global fit analysis detected 19 (F1.stat) or 24 (F2. stat) statistically significant coevolving host-parasite pairs, depending on the statistics used (calculating ligandreceptor relation importance in F1.stat or using a nonpermutated matrix in F2.stat), and resulting in a global fit of 0.2281377 with highly significant $P$-value of 0.001 over 999 permutations (Additional file 10: Table S9). 


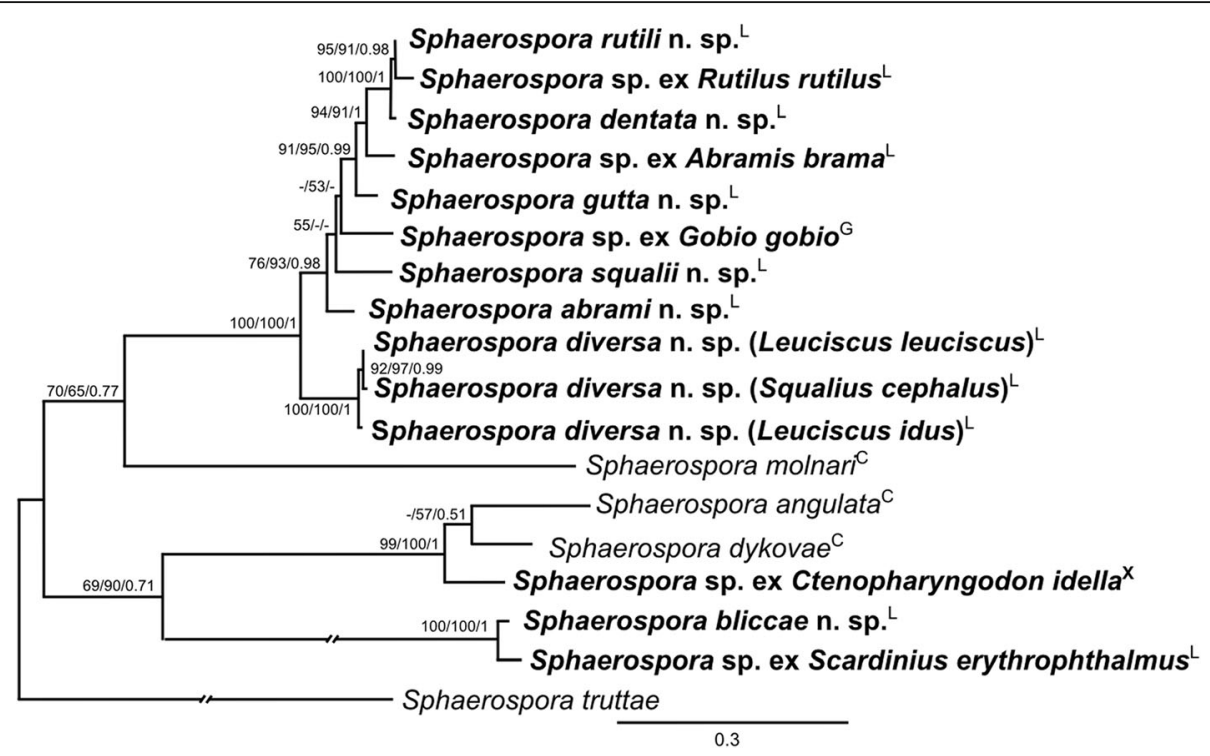

Fig. 4 18S rDNA-based maximum likelihood (GTR $+\lceil$ model) tree of Sphaerospora spp. from fish from the order Cypriniformes, with Sphaerospora truttae used as the outgroup. Newly sequenced taxa are in bold. Maximum likelihood/maximum parsimony/Bayesian inference support values are shown at every node. Dashes indicate $<50$ nodal support values or a node missing in the maximum parsimony and Bayesian inference analyses. The original length of long branches was shortened to $50 \%$ of their original length (indicated as $-/ /-$-). Superscript letters at the end of the species names indicate their attribution to the particular family (C, Cyprinidae; G, Gobionidae; L, Leuciscidae; X, Xenocyprididae)

\section{Discussion}

\section{Sphaerospora (s.s.) biodiversity, phylogeny and host} specificity

Due to the difficulty of amplifying the strongly divergent sequences and extremely long, species-specific insertions by PCR, a condition that is further complicated by myxozoan co-infections in kidneys, Sphaerospora (s.s.) $18 S$ rDNA sequence data has long been scarce [5]. Based on the development of new primers ([5], present study), the Sphaerospora (s.s.) clade was enlarged from 19 [5, 7, 9, $53]$ to 36 species. Based on $18 S$ rDNA sequence divergence criteria proposed for other myxozoans [54-56], $<1 \%$ divergence was considered conspecific for $S$. diversa n. sp. (3 sequences; this study) and > 1\% was considered interspecific variation [56]. However, species-specific long insertions in $18 S$ rDNA cause extremely high sequence divergence (1.87-59.00\%) in sphaerosporids, thereby greatly facilitating the differentiation, even of closely related species. Phylogenetic analyses of the enriched dataset showed clustering of the newly obtained sequences in previously established clades, and their GC content matched the previously recognized difference for the two main sphaerosporid clades [5]. However, some additional key findings were revealed in this study. Sphaerospora elopi n. sp. from an evolutionary older teleost, $E$. saurus (Elopiformes), represents presently the most basal species of "primary marine" sphaerosporids. The "anadromous host" clade of Bartošová et al. [5] was enriched by Sphaerospora spp. from freshwater fishes
L. lota, S. lucioperca and L. gibbosus. Sphaerospora truttae is the only species with anadromous hosts (Salmo salar L. and Salmo trutta L.) in this clade but infects its hosts only in freshwater [57]. Moreover, since S. elegans $18 S$ rDNA was sequenced from Gasterosteus aculeatus from an isolated freshwater site (A. Holzer, pers. comm.) and Pomoxis nigromaculatus (Lesueur, 1829) is a freshwater species, this clade can be considered as a "true" freshwater clade, justifying the changed attribute "mixed host clade". Important biodiversity and data enrichment for sphaerosporids from cypriniform hosts (12 new species) allows the interpretation of the clustering of a large number of sphaerosporids from closely related hosts and statements on host specificity. The long branch created by S. diminuta probably represents a novel sublineage rather than a phylogenetic artefact, as variable regions (specifically V4 and V5) and GC content are distinct from the rest of the other sphaerosporids (Additional file 6: Table S5). However, Sphaerospora sp. from $P$. nigromaculatus clusters sister to $S$. diminuta, from another centrarchiform host, L. gibbosus. Further taxon sampling from this fish family could resolve the long branch position of $S$. diminuta in the future.

Central European cypriniforms were suggested as a Sphaerospora biodiversity hostspot $[41,42]$ long before DNA sequencing became accessible. Our molecular data confirm this observation, further suggesting that even morphologically indistinguishable species from different hosts [24] can represent different species. 


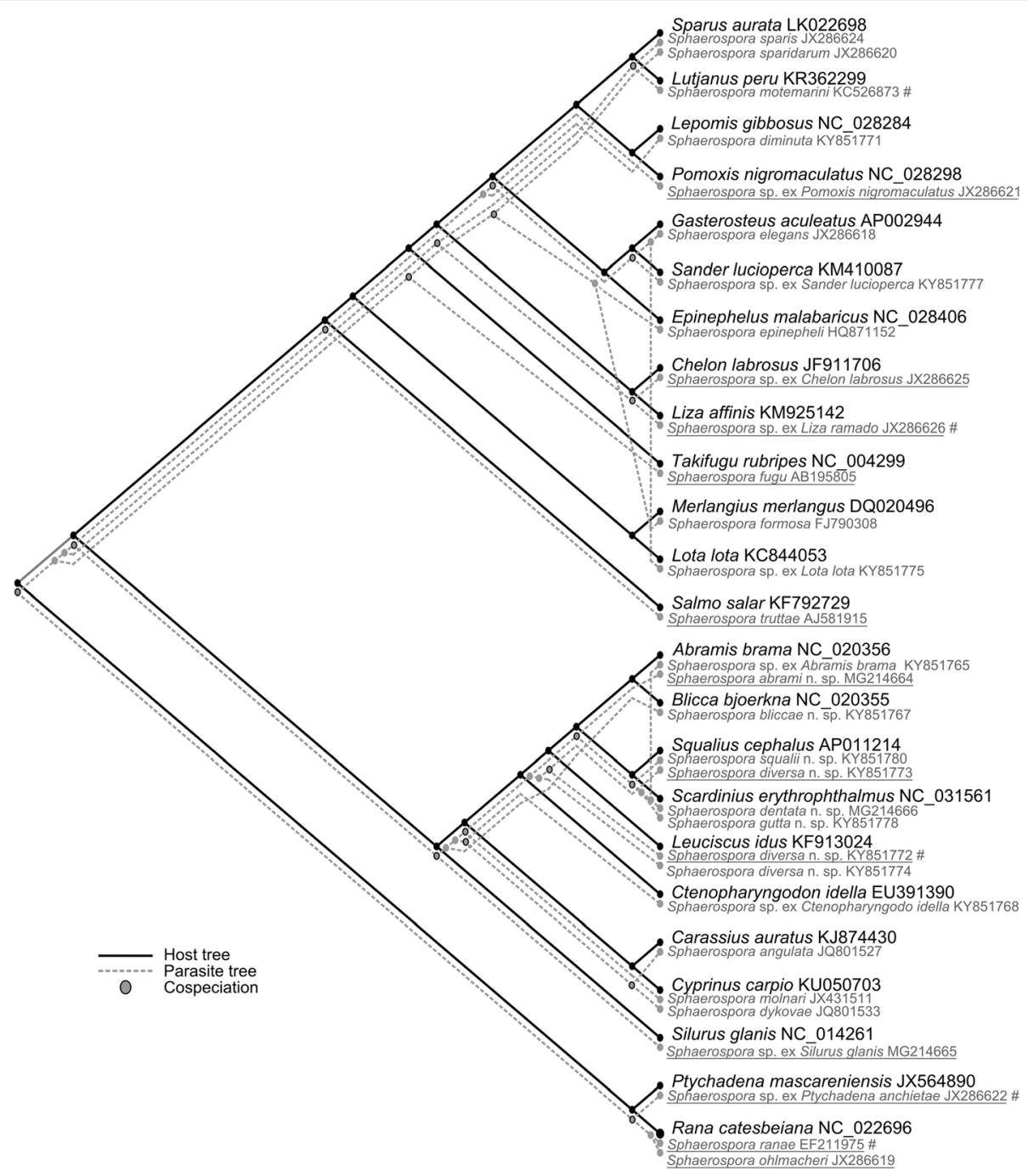

Fig. 5 Cophylogeny reconstruction of Sphaerospora spp. (18S rDNA sequences) and their vertebrate hosts (full mitogenome sequences), using CoRe-PA. Vertebrate maximum likelihood (ML) tree shown in black and parasite ML tree as grey dashed lines. \# indicates that sequence data of a closely related vertebrate host were used for the analysis, as complete mitogenome data were unavailable for this specific host. Underlined names indicate host-parasite cophylogeny detected by ParaFit

DNA sequencing demonstrates rather strict host specificity as a general rule in sphaerosporids $([5,24]$, present study). Hence, reports of single species in multiple unrelated hosts $[40,58-61]$ require confirmation by DNA sequencing. Strict host specificity has few exceptions, but only involves closely related hosts: Sphaerospora epinepheli Supamattaya, Fischer-Scherl, Hoffmann \& Boonyaratpalin, 1991 in Epinephelus malabaricus (Block \& Schneider, 1801) and Epinephelus coioides (Hamilton, 1822) [53, 62], Sphaerospora angulata Fujita, 1912 in Carassius auratus (L.) and Carassius gibelio (Bloch, 1782) [24], S. truttae in S. salar and S. trutta [14, 63], and S. diversa n. sp. in three closely related [64] leuciscinids (present study). Interestingly, identical $18 S \mathrm{rDNA}$ sequences of $S$. diversa were obtained from two L. leuciscus specimens of different geographical origin (Table 1) but intraspecific sequences divergence from all three hosts ranged between 0.29-0.89\% (Additional file 8: Table S7). These differences may well represent another diversification step of sphaerosporids within leuciscinid hosts, especially because the sphaerosporid sequences from $L$. leuciscus and S. cephalus were obtained from the same sampling site (Table 1), hence potentially indicating first stages of host-mediated diversification, as observed in Myxobolus pseudodispar Gorbunova, 1936 [65]. Cypriniforms are hosts of multiple sphaerosporids (Table 1), potentially indicating hyperdiversification of sphaerosporids in cypriniforms, which is also highly pronounced in myxobolids [16]. 


\section{Biological characteristics mirroring phylogenetic relationships of Sphaerospora (s.s.)}

Tissue tropism-dependent phylogenetic clustering is the most common phenomenon in myxozoans, defining a large number of subclades (reviewed by [2]). However, sphaerosporids are predominantly urinary tract-infecting parasites, with only two histozoic members sequenced to date, S. fugu from the intestinal epithelium [66] and $S$. molnari from the gill epithelium [67]. All members of the most basal myxozoan clade, the Malacosporea, are coelozoic in the renal tubules (reviewed by [56]), and sphaerosporids share this location as their preferred intrapiscine site. This indicates that renal tubules are an ancestral localization $[5,68]$. In sphaerosporids, a switch to a histozoic development happened at least twice independently, in S. fugu and in S. molnari [4, 9]. Various sphaerosporids have been reported from unusual sites such as the eye [40], gall-bladder [69-73], gills [40, 67, $74,75]$, intestine $[40,51,69,76-78]$, muscle [58], oral cavity [58], ovary $[37,79,80]$ and skin [75], without molecular characterisation. Although the present study was focused on the urinary system, the main infection site of sphaerosporids in fish, the abovementioned organs should be analysed in further Sphaerospora molecular research. Sequence data from these species could determine how many times the histozoic type of development evolved in sphaerosporids and if tissue tropism-related phylogenetic clustering exists. The lack of tissue-tropism diversity in sphaerosporids led us to investigate other patterns such as geography, which was not found to mirror the phylogenetic tree of this group (Fig. 3) though important for the clustering of other myxozoans, especially at the species level [54, 81-83]. Host habitat and host order clearly reflect sphaerosporid clustering, similar to other myxozoan clades (e.g. [84-86]).

\section{Coevolution of species of Sphaerospora (s.s.) and their vertebrate hosts}

Phylogenetic clustering of sphaerosporids according to host order led us to investigate host-parasite codivergence in this clade of myxozoans and to unravel the evolutionary history of sphaerosporids. Cophylogenetic analyses showed highly significant congruence between the phylogeny of sphaerosporids and their vertebrate hosts, by both, tree topology-based and distance-based methods. Although distance-based methods are considered less biased [87], using a smaller dataset of 19 hosts and 19 sphaerosporids [16] did not result in a significant outcome when using $16 \mathrm{~S}$ mtRNA data, likely because this limited host dataset showed similar distances between taxa. Holzer et al. [16] showed that full mitogenome host data improve the outcome of distance-based methods but had only limited parasite sequences available and mitogenome data was not analysed at the species level. In our mitogenome-based host phylogeny, all taxa except Takifugu rubripes (Temminck \& Schlegel) clustered according to the most updated fish phylogeny inferred using genomic data of nearly 2000 fishes [52]. The improved taxon sampling and more informative host dataset used in the present study hence considerably improved the outcome of cophylogenetic studies. Especially interesting is the finding that cypriniforms are a "preferred" host group with multiple parasite lineages in individual hosts. This appears to support the finding that hyperdiverse host fish groups (Ostariophysi and Percomorpha) [88] show a pronounced potential for parasite diversification [16], also in sphaerosporids. A higher potential of parasite sharing between closely related hosts $[89,90]$ and host-driven diversification was observed in Sphaerospora spp. in leuciscinids in the present study. Closely related cypriniforms are among the most abundant fish groups in European freshwaters [91, 92], often sharing the same habitat. This allows diversification of relatively host-specific taxa such as Sphaerospora (s.s.) spp., hence explaining the high biodiversity of sphaerosporids in these habitats, though sampling bias cannot be excluded at present [93].

\section{Evolutionary history of sphaerosporids and their alternate hosts}

Holzer et al. [16] suggested that sphaerosporids likely have a marine origin and may have settled in "archiannelid" (chaetopterids or sipunculids) invertebrate hosts. The present study appears to further indicate the presence of two independent entries of sphaerosporids into archiannelids: (i) at the base of the primary marine clade; and (ii) at the root of all other sphaerosporids. This suggestion is based on the observation that elopiform fishes (Teleostei) are the oldest vertebrate hosts in the primary marine clade $[51,52]$ while tetrapods, which originated earlier than teleosts, occupy this position in the large clade harbouring all other Sphaerospora spp. It is possible that the archiannelid acquired as host in the primary marine lineage was maintained as a single host until teleosts evolved in the marine realm, while the large sphaerosporid clade appears to have a similar evolutionary history as most other myxozoan clades which accommodate cartilaginous fish as their first host group [94-96], followed by lineages in tetrapods and finally mirroring the evolution of teleosts [16]. To support this idea, it would be essential to sequence sphaerosporids from evolutionary old fish lineages such as the Chondrichthyes or even the Cyclostomata. A single species, Sphaerospora araii Arthur \& Lom, 1985 was described from a ray, Raja rhina Jordan \& Gilbert, 1880 [78], but our newly developed primer sets may be able to uncover and sequence further species in cartilaginous fishes. We believe that sphaerosporids from cartilaginous 
fishes represent missing links that would be able to confirm phylogenetic congruence of sphaerosporids and their vertebrate hosts and contribute further information on their common evolutionary history.

\section{Conclusions}

The present study aimed at elucidating the phylogeny and evolutionary history of Sphaerospora (s.s.), based on a greatly enlarged (almost doubled) dataset of difficult to amplify $18 S \mathrm{rDNA}$ sequences. Larger datasets including information of new host groups and habitats provided important data, explaining parasite phylogenetic clustering. We report a very narrow host specificity for sphaerosporids. Sphaerospora diversa n. sp. sequenced from three closely related leuciscinid species showed low sequence divergences, presumably reflecting initial hostdriven diversification while the remainder of the newly sequenced species were strictly host-specific. Cypriniforms are characterized by multiple parasite lineages, indicating successful parasite diversification within this host group. Cophylogenetic analyses revealed significant phylogenetic congruence between sphaerosporids and their vertebrate hosts. Based on cophylogenetic analysis, we suggest that parasite entry to invertebrate hosts occurred twice independently during sphaerosporid evolution. Sequencing of sphaerosporids from cartilaginous fish, or other evolutionary older vertebrate groups could substantially support this idea and further elucidate the evolutionary history of this group of fast evolving myxozoans.

\section{Additional files}

Additional file 1: Table S1. List of fish hosts examined for Sphaerospora spp. infections with information about locality, number of fish examined, parasite prevalence (positive samples in a black box) and estimated age from the total length. (DOCX $51 \mathrm{~kb}$ )

Additional file 2: Table S2. List of PCR primer combinations and other PCR details applied to amplify 185 rDNA sequences of different sphaerosporids. (DOCX $50 \mathrm{~kb}$ )

Additional file 3: Table S3. Newly designed primers used in this study. (DOCX $28 \mathrm{~kb}$ )

Additional file 4: Table S4. PCR cycling parameters used for sphaerosporid amplification. (DOCX $28 \mathrm{~kb}$ )

Additional file 5. 185 rDNA dataset (fasta format) of 4813 bp long Sphaerospora (s.s.) sequences. (FASTA $190 \mathrm{~kb}$ )

Additional file 6: Table S5. The lengths of variable regions (base pairs) and GC-content (percentage; in parenthesis) of newly obtained 18S rDNA Sphaerospora sequences (bold numbers indicate the highest values). (DOCX $32 \mathrm{~kb}$ )

Additional file 7: Table S6. 185 rDNA sequence dissimilarities of Sphaerospora (s.s.) species. Almost complete sequences are compared only. (XLSX $15 \mathrm{~kb}$ )

Additional file 8: Table S7. 185 rDNA sequence dissimilarities (based on complete sequence dataset of $3112 \mathrm{bp}$ ) of Sphaerospora diversa $\mathrm{n}$. sp. from three host species. (XLSX $9 \mathrm{~kb}$ )

Additional file 9: Table S8. List of members of Sphaerospora (s.s.) clade (18S rDNA), their vertebrate hosts (complete mitogenome) and GenBank accession numbers (18S rDNA for sphaerosporids and complete mitogenome for vertebrate host) used for cophylogeny studies (CoRe-Pa and Parafit analysis). (DOCX $33 \mathrm{~kb}$ )

Additional file 10: Table S9. ParaFit analysis (performed in APE package v3.4 in R v3.2.4) result for sphaerosporids and their vertebrate hosts. Statistically significant results $(<0.050)$ are indicated in bold. Test statistics were calculated (i) between the of sums of squares of values in the main diagonal of the combined host-parasite matrix and a matrix with unspecific interaction to estimate the ligand-receptor relation which is more restricted and preferred value (F1.stat), and (ii) the difference calculated by the trace of non-permutated matrix (F2.stat). (DOCX $34 \mathrm{~kb}$ )

\section{Abbreviations}

BI: Bayesian inference; LSID: Life Science Identifier; ML: Maximum likelihood analysis; MP: Maximum parsim">Polar capsule length; PW: Polar capsule width; L: Spore length; T: Spore thickness; L/T ratio: Spore length to thickness ratio

\section{Acknowledgements}

We are thankful to Dr Ana Born-Torrijos (Institute of Parasitology, BC CAS, České Budějovice, Czech Republic) for assistance with cophylogeny analysis in R, Dr Ashlie Hartigan (Natural History Museum, Life Science Department, London) for assistance with fish dissection, Dr Pavel Jurajda (Institute of Vertebrate Biology, CAS, Brno, Czech Republic), Dr Aneta Kostadinova (Institute of Parasitology, BC CAS, České Budějovice, Czech Republic), Dr Monica Caffara (Department of Veterinary Medical Sciences, University of Bologna, Italy), Dr Nathan Brennan (Mote Marine Laboratory, Sarasota, Florida), Dr Petr Blábolil (Institute of Hydrobiology, BC CAS, České Budějovice, Czech Republic), and Ing. Jan Holický for providing fish from different geographical regions. We kindly thank the editor and the anonymous referees for their valuable comments.

\section{Funding}

We acknowledge financial support by the Czech Science Foundation (grant numbers 505/12/G112 and 16-20744S), the European Commission (634429, ParaFish(ontrol). We acknowledge additional financial support by the Hungarian National Research, Development and Innovation Office (project Nr. K112301) for sampling and sample processing in Hungary.

\section{Availability of data and materials}

The data supporting the conclusions of this article are provided within the article and its Additional files S1-S10. 18S rDNA sequences $(n=22)$ of the new Sphaerospora spp. obtained from different fish hosts were submitted to the GenBank database under the accession numbers KY851765-KY851780, KY863519-KY863520, MF347687 and MG214664-MG214666. Hapantotypes, represented by series of phototypes, spore diagrams and representative DNA samples of all new Sphaerospora spp. and Sphaerospora diminuta were deposited in the Protistological Collection of the Institute of Parasitology, Biology Centre, Czech Academy of Sciences, České Budějovice under the accession numbers IPCAS Prot 44-52.

\section{Authors' contributions}

ASH conceived and designed the study. SP, PBS, IF, ASH and EE were responsible for the fish sampling, dissection, microscopic examination, morphological data documentation. SP and HP performed DNA extraction, PCR screening, sequencing. SP and ASH performed sequence alignments, primer design, cophylogenetic analyses. IF conducted phylogenetic analyses. SP prepared line drawings, figure plates, tables and additional files. SP, ASH and PBS drafted the manuscript. All authors read and approved the final manuscript.

\section{Ethics approval}

All animals were treated in accordance with the Animal Protection Laws of the Czech Republic No. 246/1992 Sb., ethics approval issued by the ethical committees at the BC CAS, the State Veterinary Administration, and the Central Commission for Animal Welfare under protocol No. 095/2012.

\section{Competing interests}

The authors declare that they have no competing interests. 


\section{Publisher's Note}

Springer Nature remains neutral with regard to jurisdictional claims in published maps and institutional affiliations.

\section{Author details}

'Institute of Parasitology, Biology Centre, Czech Academy of Sciences, 37005 České Budějovice, Czech Republic. ${ }^{2}$ Faculty of Science, University of South Bohemia, 37005 České Budějovice, Czech Republic. ${ }^{3}$ Institute for Veterinary Medical Research, Centre for Agricultural Research, Budapest H-1143, Hungary.

\section{Received: 26 December 2017 Accepted: 23 April 2018}

Published online: 15 June 2018

\section{References}

1. Zhang ZQ. Animal biodiversity: An introduction to higher-level classification and taxonomic richness. Zootaxa. 2011;3148:7-12.

2. Fiala I, Bartošová-Sojková P, Whipps CM. Classification and phylogenetics of Myxozoa. In: Okamura B, Gruhl A, Bartholomew JL, editors. Myxozoan evolution, ecology and development. Cham Heidelberg New York Dordrecht London: Springer International Publishing AG Switzerland; 2015 p. 85-110. https://doi.org/10.1007/978-3-319-14753-6_5.

3. Lom J, Dyková I. Myxozoan genera: definition and notes on taxonomy, lifecycle terminology and pathogenic species. Folia Parasitol. 2006:53:1-36.

4. Jirků M, Fiala I, Modrý D. Tracing the genus Sphaerospora: rediscovery, redescription and phylogeny of the Sphaerospora ranae (Morelle, 1929) $n$. comb. (Myxosporea, Sphaerosporidae), with emendation of the genus Sphaerospora. Parasitology. 2007;134:1727-39.

5. Bartošová $P$, Fiala I, Jirků M, Cinková $M$, Caffara $M$, Fioravanti $M L$, et al. Sphaerospora sensu stricto: Taxonomy, diversity and evolution of a unique lineage of myxosporeans (Myxozoa). Mol Phylogenet Evol. 2013;68:93-105.

6. Holzer AS, Pecková H, Patra S, Brennan NP, Yanes-Roca C, Main KL. Severe glomerular disease in juvenile grey snapper Lutjanus griseus $L$. in the Gulf of Mexico caused by the myxozoan Sphaerospora motemarini n. sp. Int J Parasitol Parasites Wildl. 2013:2:124-30.

7. Sanders JL, Jaramillo AG, Ashford JE, Feist SW, Lafferty KD, Kent ML. Two myxozoans from the urinary tract of topsmelt, Atherinops affinis. J Parasitol. 2015;101:577-86.

8. Holzer AS, Wootten R, Sommerville C. The secondary structure of the unusually long 185 ribosomal RNA of the myxozoan Sphaerospora truttae and structural evolutionary trends in the Myxozoa. Int J Parasitol. 2007:37:1281-95.

9. Eszterbauer E, Sipos D, Forró B, Bartošová P, Holzer A. Molecular characterization of Sphaerospora molnari (Myxozoa), the agent of gill sphaerosporosis in common carp Cyprinus carpio. Dis Aquat Organ. 2013;104:59-67.

10. Jirků M, Bartošová-Sojková P. Ultrastructure and localisation of latesporogonic developmental stages of Sphaerospora ranae (Myxosporea: Sphaerosporidae). Folia Parasitol. 2014;61:311-21.

11. Özer A, Wootten R. The life cycle of Sphaerospora truttae (Myxozoa: Myxosporea) and some features of the biology of both the actinosporean and myxosporean stages. Dis Aquat Organ. 2000;40:33-9.

12. Molnár K, El-Mansy A, Székely C, Baska F. Experimental identification of the actinosporean stage of Sphaerospora renicola Dyková \& Lom, 1982 (Myxosporea: Sphaerosporidae) in oligochaete alternate hosts. J Fish Dis. 1999;22:143-53.

13. Holzer AS, Sommerville C, Wootten R. Molecular relationships and phylogeny in a community of myxosporeans and actinosporeans based on their 18S rDNA sequences. Int J Parasitol. 2004;34:1099-111.

14. Eszterbauer E, Marton S, Rácz OZ, Letenyei M, Molnár K. Morphological and genetic differences among actinosporean stages of fish-parasitic myxosporeans (Myxozoa): difficulties of species identification. Sys Parasitol. 2006;65:97-114.

15. Desser SS, Lom J, Dyková I. Developmental stages of Sphaerospora ohlmacheri (Whinery, 1893) n. comb. (Myxozoa:Myxosporea) in the renal tubules of bullfrog tadpoles, Rana catesbeiana, from Lake of Two Rivers, Algonquin Park, Ontario. Can J Zool. 1986;64:2213-7.

16. Holzer AS, Bartošová-Sojková P, Born-Torrijos A, Lövy A, Hartigan A, Fiala I. The joint evolution of the Myxozoa and their alternate hosts: a cnidarian recipe for success and vast biodiversity. Mol Ecol. 2018;27:1651-66.

17. Jiménez-Guri E, Philippe H, Okamura B, Holland PWH. Buddenbrockia is a cnidarian worm. Science. 2007;317:116-8.
18. Evans NM, Holder MT, Barbeitos MS, Okamura B, Cartwright P. The phylogenetic position of Myxozoa: exploring conflicting signals in phylogenomic and ribosomal data sets. Mol Biol Evol. 2010;27:2733-46.

19. Chang ES, Neuhof M, Rubinstein ND, Diamant A, Philippe H, Huchon D, et al. Genomic insights into the evolutionary origin of Myxozoa within Cnidaria. Proc Natl Acad Sci USA. 2015:112:14912-7.

20. Takeuchi F, Sekizuka T, Ogasawara Y, Yokoyama H, Kamikawa R, Inagaki Y, et al. The mitochondrial genomes of a myxozoan genus Kudoa are extremely divergent in Metazoa. PLoS One. 2015;10:e0132030.

21. Lom J, Arthur JR. A guideline for the preparation of species descriptions in Myxosporea. J Fish Dis. 1989;12:151-6.

22. Sitja-Bobadilla A, Alvarez-Pellitero P. Revised classification and key species of the genus Sphaerospora Davies, 1917 (Protozoa: Myxosporea). Res Rev Parasitol. 1994;54:67-80.

23. Asahida T, Kobayashi T, Saitoh K, Nakayama I. Tissue preservation and total DNA extraction from fish stored at ambient temperature using buffers containing high concentration of Urea. Fish Sci. 1996;62:727-30.

24. Holzer AS, Bartošová P, Pecková H, Tyml T, Atkinson S, Bartholomew J, et al. 'Who's who' in renal sphaerosporids (Bivalvulida: Myxozoa) from common carp, Prussian carp and goldfish - molecular identification of cryptic species, blood stages and new members of Sphaerospora sensu stricto. Parasitology. 2013;140:46-60

25. Katoh K, Misawa K, Kuma K, Miyata T. MAFFT: a novel method for rapid multiple sequence alignment based on fast Fourier transform. Nucleic Acids Res. 2002;30:3059-66.

26. Kearse M, Moir R, Wilson A, Stones-Havas S, Cheung M, Sturrock S, et al. Geneious Basic: an integrated and extendable desktop software platform for the organization and analysis of sequence data. Bioinformatics. 2012;28:1647-9.

27. Stamatakis A. RAxML-VI-HPC: Maximum likelihood-based phylogenetic analyses with thousands of taxa and mixed models. Bioinformatics. 2006:22:2688-90.

28. Posada D. JModelTest: phylogenetic model averaging. Mol Blol Evol. 2008; 25:1253-6.

29. Swofford DL. PAUP*. Phylogenetic Analysis Using Parsimony (*and other methods). Version 4. Sunderland, Massachusetts: Sinauer Associates; 2002

30. Ronquist F, Huelsenbeck JP. MrBayes 3: Bayesian phylogenetic inference under mixed models. Bioinformatics. 2003:19:1572-4.

31. Rambaut A, Suchard MA, Xie D, Drummond AJ. Tracer v1.6. 2014 URL http://tree.bio.ed.ac.uk/software/tracer/.

32. Merkle D, Middendorf M, Wieseke N. A parameter-adaptive dynamic programming approach for inferring cophylogenies. BMC Bioinformatics. 2010;11(Suppl. 1):S60.

33. Legendre $P$, Desdevises $Y$, Bazin E. A statistical test for host-parasite coevolution. Syst Biol. 2002;51:217-34.

34. Paradis E, Claude J, Strimmer K. APE: analyses of phylogenetics and evolution in R language. Bioinformatics. 2004;20:289-90.

35. Li LX, Desser SS. The protozoan parasites of fish from two lakes in Algonquin Park, Ontario. Can J Zool. 1985;63:1846-58.

36. Lom J, Desser SS, Dyková I. Some little-known and new protozoan parasites of fish from Lake Sasajewun, Algonquin Park, Ontario. Can J Zool. 1989;67:1372-9.

37. Xiao C, Desser SS. Sphaerospora ovophila n. sp. and Myxobolus algonquinensis n. sp. (Myxozoa, Myxosporea), ovarian parasites of fish from Algonquin Park, Ontario, Canada. J Eukaryot Microbiol. 1997:44:157-61.

38. ICZN. International Commission on Zoological Nomenclature: Amendment of articles 8, 9, 10, 21 and 78 of the International Code of Zoological Nomenclature to expand and refine methods of publication. Bull Zool Nomencl. 2012:69:161-9.

39. El-Matbouli M, Hoffmann R, Kern R. Sphaerospora bramae sp. nov. (Myxosporea: Sphaerosporidae) in the kidney of common bream (Abramis brama). Bull Eur Ass Fish Pathol. 1995;15:197-9.

40. Kudo R. Studies on Myxosporidia. A synopsis of genera and species of Myxosporidia. III Biol Monogr. 1919;5:1-265.

41. Lom J, Pavlásková M, Dyková I. Notes on kidney-infecting species of the genus Sphaerospora Thélohan (Myxosporea), including a new species $S$. gobionis sp. nov., and on myxosporean life cycle stages in the blood of some freshwater fish. J Fish Dis. 1985:8:221-32.

42. Baska F, Molnár K. Blood stages of Sphaerospora spp. (Myxosporea) in cyprinid fishes. Dis Aquat Organ. 1988:5:23-8.

43. El-Matbouli M, Hoffmann RW. Sphaerospora scardinii n. sp. (Myxosporea, Sphaerosporidae) observed in the kidney of rudd Scardinius erythrophthalmus. Dis Aquat Organ. 1992;14:23-9. 
44. Longshaw M. Studies of myxozoan parasites of freshwater fish and invertebrate hosts. PhD Thesis. England: University of Plymouth; 2004. p. 355.

45. Zaika VE. The question of endemicity among the parasites of the fishes in Lake Baikal. Dokl Akad Nauk SSSR. 1961;141:236-9. (In Russian)

46. Molnár K. Renal sphaerosporosis in the common carp Cyprinus carpio L. J Fish Dis. 1980:3:11-9.

47. Hanajavanit C, Bermingham M, Mulcahy MF. Epidemiology of squamous cel carcinomas in rudd Scardinius erythrophthalmus from SE Ireland. Dis Aquat Organ. 2008:80:145-56.

48. Kulemina IV. New species of endoparasitic protozoa from the fry of the Lake Seliger. Zool Zh. 1969;48:1295-8.

49. Kashkovsky W, Razmashkin DA, Skripchenko GE. Diseases and parasites of fishes in Siberian and Ural fish farms. Sverdlovsk: Sredne-Uralskoe Knizhnoe Izdatelstvo; 1974. (In Russian)

50. Kepr T. Parasitic Protozoa of cyprinid fishes: Protozoa of the roach Rutilus rutilus (Linnaeus, 1758) in Czechoslovakia. Folia Parasitol. 1991;38:11-21.

51. Near TJ, Eytan RI, Dornburg A, Kuhn KL, Moore JA, Davis MP, et al. Resolution of ray-finned fish phylogeny and timing of diversification. Proc Natl Acad Sci USA. 2012;109:13698-703.

52. Betancur-R R, Wiley EO, Arratia G, Acero A, Bailly N, Miya M, et al. Phylogenetic classification of bony fishes. BMC Evol Biol. 2017;17:162.

53. U-Taynapun K, Chirapongsatonkul N, Maneesaay P, Itami T, Tantikitti C. A new host record of Sphaerospora epinepheli (Myxosporea: Bivalvulida) occurring on orange-spotted grouper Epinephelus coioides from Thailand: epidemiology, histopathology and phylogenetic position. Vet Parasitol. 2012;188:215-24.

54. Whipps CM, Kent ML. Phylogeography of the cosmopolitan marine parasite Kudoa thyrsites (Myxozoa: Myxosporea). J Eukaryot Microbiol. 2006:53:364-73.

55. Bartošová P, Fiala I. Molecular evidence for the existence of cryptic species assemblages of several myxosporeans (Myxozoa). Parasitol Res. 2011:108:573-83

56. Patra S, Hartigan A, Morris DJ, Kodádková A, Holzer AS. Description and experimental transmission of Tetracapsuloides vermiformis n. sp. (Cnidaria: Myxozoa) and guidelines for describing malacosporean species including reinstatement of Buddenbrockia bryozoides n. comb. (syn. Tetracapsula bryozoides). Parasitology. 2017;144:497-511.

57. McGeorge JM, Sommerville C, Wootten R. Epizootiology of Sphaerospora truttae (Myxozoa: Myxosporea) infections of Atlantic salmon Salmo salar at freshwater smolt producing hatcheries in Scotland. Dis Aquat Organ. 1996;26:33-41.

58. Fantham HB, Porter A, Richardson LR. Some myxosporidia found in certain freshwater fishes in Quebec Province, Canada. Parasitology. 1939;31:1-77.

59. Shul'man SS. Myxosporidia of the USSR. Moscow-Lenningrad: Nauka Publishers. Translated version published for the United States Department of the Interior and National Science Foundation. New Delhi: Amerind Publishing Co. Pvt. Ltd; 1966. p. 631

60. Molnár K. Sphaerospora danubialis sp. n. (Myxosporea: Sphaerosporidae) from the kidney of freshwater percid fishes. Parasitol Hung. 1991;24:53-8.

61. Fomena A, Bouix G. New Myxosporidea species (Myxozoa) from freshwater teleosts in southern Cameroon (Central Africa). J Afr Zool. 1994;108:481-91.

62. Supamattaya K, Fischerscherl T, Hoffmann RW, Boonyaratpalin S. Sphaerospora epinepheli n. sp. (Myxosporea: Sphaerosporidae) observed in grouper (Epinephelus malabaricus). J Protozool. 1991;38:448-54.

63. Holzer AS, Sommerville C, Wootten R. Molecular studies on the seasonal occurrence and development of five myxozoans in farmed Salmo trutta L. Parasitology. 2006;132:193-205.

64. Stout CC, Tan M, Lemmon AR, Lemmon EM, Armbruster JW. Resolving Cypriniformes relationships using an anchored enrichment approach. BMC Evol Biol. 2016:16:244.

65. Forró B, Eszterbauer E. Correlation between host specificity and genetic diversity for the muscle-dwelling fish parasite Myxobolus pseudodispar: examples of myxozoan host-shift? Folia Parasitol. 2016;63:019.

66. Tun T, Yokoyama H, Ogawa K, Wakabayashi H. Myxosporeans and their hyperparasitic microsporeans in the intestine of emaciated tiger puffer. Fish Pathol. 2000;35:145-56.

67. Lom J, Dyková I, Pavlásková M, Grupcheva G. Sphaerospora molnari sp. n (Myxozoa, Myxosporea), an agent of gill, skin and blood sphaerosporosis of common carp in Europe. Parasitology. 1983;86:529-35.

68. Fiala I, Bartošová P. History of myxozoan character evolution on the basis of rDNA and EF-2 data. BMC Evol Biol. 2010;10:13.
69. Cohn L. Zur Kenntniss der Myxosporidien. Zentralbl Bakter Parasitenkd. 1902;1:628-32.

70. Fantham HB, Porter A. On a myxosporidian. Sphærospora periophthalmi, sp. n., found in African and Indian Mudskippers (Pisces), and its possible significance. Proc Zool Soc Lond. 1943;112:113-9.

71. Moser M, Kent ML, Dennis D. Gall-bladder Myxosporea in coral-reef fishes from Heron Island, Australia. Aust J Zool. 1989;37:1-13.

72. Sarkar NK, Ghosh S. Two new coelozoic Myxosporida (Myxozoa: Myxosporea) from estuarine teleost fishes (Mugilidae) of West Bengal, India. Proc Zool Soc Calcutta. 1991;44:131-5.

73. Brickle P, Kalavati C, MacKenzie K. Two new species of myxozoan parasites (Myxosporea, Bivalvulida) from toothfish Dissostichus eleginoides Smitt, 1898 (Pisces, Nototheniidae). Acta Parasitol. 2001;46:250-3.

74. Su X, White RWG. New myxosporeans (Myxozoa: Myxosporea) from marine fishes of Tasmania, Australia. Acta Protozool. 1994:33:251-9.

75. Chen C, Ma C. Myxozoa, Myxosporea. Fauna Sinica. Beijing: Science Press; 1998. p. 993.

76. Jacob E, Bremen HB. Eine bislang unbekannte Sphaerosporose des Flussaals, hervorgerufen durch Sphaerospora reichenowi nova species, mit eigenartigem Sitz im Darm. Berl Munch Tierarztl Wochenschr. 1953;66:326-8.

77. Chen C, Hsieh S. A new genus and two new species of family Myxobolidae from freshwater fishes of China (Myxosporidia: Myxobolidae). Acta Zootaxon Sinica. 1984;9:113-7.

78. Arthur JR, Lom J. Sphaerospora araii n. sp. (Myxosporea: Sphaerosporidae) from the kidney of a longnose skate (Raja rhina Jordan and Gilbert) from the Pacific Ocean off Canada. Can J Zool. 1985;63:2902-6.

79. Schuurmans-Stekhoven JJH. Über einige Myxosporidien des Stichlings. Arch Protistenk. 1920;41:321-9.

80. Moshu AY. Description of Sphaerospora luciopercae sp. n. (Protista: Myxosporea) - parasite of the European pikeperch Stizostedion lucioperca (L.). Bul Akad Stiinte Republicci Moldova. Stinnte Biologice si Chimice. 1992;2:54-6.

81. Whipps CM, Adlard RD, Bryant MS, Lester RJG, Findlay V, Kent ML. First report of three Kudoa species from eastern Australia: Kudoa thyrsites from mahi mahi (Coryphaena hippurus), Kudoa amamiensis and Kudoa minithyrsites n. sp. from sweeper (Pempheris ypsilychnus). J Eukaryot Microbiol. 2003;50:215-9.

82. Henderson M, Okamura B. The phylogeography of salmonid proliferative kidney disease in Europe and North America. Proc R Soc Lond B-Biol Sci. 2004;271:1729-36

83. Liu XH, Batueva MD, Zhao YL, Zhang JY, Zhang QQ, Li TT, et al. Morphological and molecular characterisation of Myxobolus pronini n. sp. (Myxozoa: Myxobolidae) from the abdominal cavity and visceral serous membranes of the gibel carp Carassius auratus gibelio (Bloch) in Russia and China. Parasit Vectors. 2016:9:562.

84. Fiala I. The phylogeny of Myxosporea (Myxozoa) based on small subunit ribosomal RNA gene analysis. Int J Parasitol. 2006:36:1521-34.

85. Gunter N, Adlard R. The demise of Leptotheca Thélohan, 1895 (Myxozoa: Myxosporea: (eratomyxidae) and assignment of its species to Ceratomyxa Thélohan, 1892 (Myxosporea: Ceratomyxidae), Ellipsomyxa Køie, 2003 (Myxosporea: Ceratomyxidae), Myxobolus Bütschli, 1882 and Sphaerospora Thélohan, 1892 (Myxosporea: Sphaerosporidae). Syst Parasitol. 2010;75:81-104.

86. Alama-Bermejo G, Raga JA, Holzer AS. Host-parasite relationship of Ceratomyxa puntazzi n. sp. (Myxozoa: Myxosporea) and sharpsnout seabream Diplodus puntazzo (Walbaum, 1792) from the Mediterranean with first data on ceratomyxid host specificity in sparids. Vet Parasitol. 2011;182:181-92.

87. de Vienne DM, Refrégier G, López-Villavicencio M, Tellier A, Hood ME, Giraud T. Cospeciation vs host-shift speciation: methods for testing, evidence from natural associations and relation to coevolution. New Phytol. 2013;198:347-85.

88. Vega GC, Wiens JJ. Why are there so few fish in the sea? P Roy Soc Lond B Biol. 2012;279:2323-9.

89. Cooper N, Griffin R, Franz M, Omotayo M, Nunn CL. Phylogenetic host specificity and understanding parasite sharing in primates. Ecol Lett. 2012;15:1370-7.

90. Huang S, Bininda-Emonds ORP, Stephens PR, Gittleman JL, Altizer S. Phylogenetically related and ecologically similar carnivores harbour similar parasite assemblages. J Anim Ecol. 2014;83:671-80.

91. Reyjol Y, Hugueny B. D. Pont, Bianco PG, Beier U, Caiola N, et al. Patterns in species richness and endemism of European freshwater fish. Global Ecol Biogeogr. 2007;16:65-75. 
92. Freyhof J, Brooks E. European Red List of freshwater fishes. Luxembourg: Publications Office of the European Union; 2011. https:/doi.org/10.2779/85903.

93. Tedersoo L, Bahram M, Dickie IE. Does host plant richness explain diversity of ectomycorrhizal fungi? Re-evaluation of Gao et al. (2013) data sets reveals sampling effects. Mol Ecol. 2014;23:992-5.

94. Gleeson R, Adlard R. Morphological and genetic analysis of three new species of Ceratomyxa Thélohan, 1892 (Myxozoa: Myxosporea) from carcharhinid sharks off Australia. Syst Parasitol. 2011;80:117-24.

95. Gleeson RJ, Adlard RD. Phylogenetic relationships amongst Chloromyxum Mingazzini, 1890 (Myxozoa: Myxosporea), and the description of six novel species from Australian elasmobranchs. Parasitol Int. 2012;61:267-74.

96. Kodádková A, Bartošová-Sojková P, Holzer AS, Fiala I. Bipteria vetusta n. sp. an old parasite in an old host: tracing the origin of myxosporean parasitism in vertebrates. Int J Parasitol. 2015;45:269-76.

97. Molnár K. Sphaerospora siluri n. sp. (Myxosporea: Sphaerosporidae) in the kidney of the sheatfish (Silurus glanis). Acta Vet Hung. 1993;41:341-7.

Ready to submit your research? Choose BMC and benefit from:

- fast, convenient online submission

- thorough peer review by experienced researchers in your field

- rapid publication on acceptance

- support for research data, including large and complex data types

- gold Open Access which fosters wider collaboration and increased citations

- maximum visibility for your research: over $100 \mathrm{M}$ website views per year

At BMC, research is always in progress.

Learn more biomedcentral.com/submissions 